\title{
Program Plan for Electron Cyclotron Heating Experiments on the ISX Tokamak
}
A. C. England
C. M. Loring
O. C. Eldridge
W. Namkung
H. C. Howe
G. L. Campen
H. L. Mitchell
D. B. Batchelor

\section{OAK RIDGE NATIONAL LABORATORY}




\section{DISCLAIMER}

This report was prepared as an account of work sponsored by an agency of the United States Government. Neither the United States Government nor any agency Thereof, nor any of their employees, makes any warranty, express or implied, or assumes any legal liability or responsibility for the accuracy, completeness, or usefulness of any information, apparatus, product, or process disclosed, or represents that its use would not infringe privately owned rights. Reference herein to any specific commercial product, process, or service by trade name, trademark, manufacturer, or otherwise does not necessarily constitute or imply its endorsement, recommendation, or favoring by the United States Government or any agency thereof. The views and opinions of authors expressed herein do not necessarily state or reflect those of the United States Government or any agency thereof. 


\section{DISCLAIMER}

Portions of this document may be illegible in electronic image products. Images are produced from the best available original document. 
Printed in the United States of America. Available from National Technical Information Service

U.S. Department of Commerce 5285 Port Royal Road, Springfield, Virginia 22161

Price: Printed Copy Microfiche $\$ 3.00$

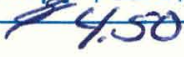

This report was prepared as an account of work sponsored by the United States Government. Neither the United States nor the Energy Research and Development Administration, nor any of their employees, nor any of their contractors, subcontractors, or their employees, makes any warranty, express or implied, or assumes any legal liability or responsibility for the accuracy, completeness or usefulness of any information, apparatus, product or process disciosed, ur repieseils that its use would not infringe privately owned rights. 
Contract No. W-7405-eng-26

FUSION ENERGY DIVISION

PROGRAM PLAN FOR ELECTRON CYCLOTRON HEATING EXPERIMENTS ON THE ISX TOKAMAK
A. C. England
C. M. Loring
0 . C. Eldridge
W. Namkung

H. C. Howe

G. L. Campen

H. L. Mitchell

D. B. Batchelor

\author{
Submitted to \\ Division of Magnetic Fusion Energy \\ Department of Energy \\ Washington, D.C. 20545 \\ Date Published - October 1977
}

NOTICE This document contains information of a preliminary nature. It is subject to revision or correction and therefore does not represent a final report.

Prepared by the
OAK RIDGE NATIONAL LABORATORY
Oak Ridge, Tennessee 37830
operated by
UNION CARBIDE CORPORATION
for the
DEPARTMENT OF ENERGY

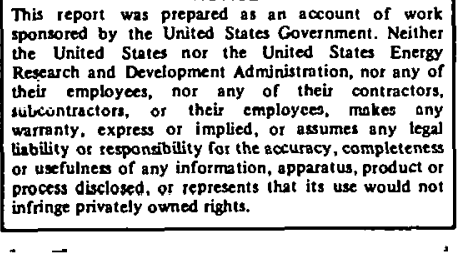


THIS PAGE

\section{WAS INTENTIONALLY \\ LEFT BLANK}




\section{CONTENTS}

Page

ABSTRACT ........................... . . v

1. INTRODUCTION AND SUMMARY .................... 1

2. JUSTIFICATION AND RATIONALE FOR THE PROPOSED EXPERIMENT. . . . 4

2.1 Basic Need: An Alternative to Neutral Injection Heating.................... 4

2.2 Additional Needs: Profile Control and Preionization. . . 5

2.3 Timing of the Experiment. . . . . . . . . . . . 6

2.4 Assessment of ECH for ISX . . . . . . . . . . 6

2.5 New Diagnostic Needs and Problems . . . ... . . . . . 7

2.6 Future Possibilities. . . . . . . . . . . . 8

3. DESCRIPTION OF THE EXPERIMENTAL EQUIPMENT. . . . . . . . . . 8

4. SAFETY ...................... . . . 12

5. ECH .PROJECT MILESTONES . . . . . . . . . . . . . . . . 14

6. COST ESTIMATES . . . . . . . . . . . . . . . . . 15

7. PERMANENT MANPOWER AND MANAGEMENT PLAN . . . . . . . . . . 17

REFERENCES ......................... . . 18

THEORETICAL APPENDIX: LINEAR THEORY OF ELECTRON

CYCLOTRON HEATING. . . . . . . . . . . . . . . . . . . . 19

A. Microwave Propagation in Tokamaks. . . . . . . . . 20

B. Electron Heating... . . . . . . . . . . . . . 24

C. Transport Simulation with Electron Heating . . . . . . . 29

REFERENCES ............................. 41 


\section{THIS PAGE}

\section{WAS INTENTIONALLY \\ LEFT BLANK}




\section{ABSTRACT}

Electron cyclotron heating (ECH) has been very successful in experiments on the ELMO mirror and bumpy torus at ORNL and on the TM-3 tokamak at Kurchatov. With the advent of high power, long pulse cyclotron masers, an experiment on a larger tokamak is proposed to determine whether ECH is a viable alternative or supplement to neutral beam heating. In combination with neutral beam heating, a unique opportunity is offered for a study of plasma transport and of the gross stability of the tokamak as the $q$ profile is altered. It is also possible to explore the high $\beta$ regime and to provide a complementary test of the principle of a flux conserving tokamak. We propose here a program of ECH on the new 0ak Ridge tokamak, ISX-B, beginning in 1978. Experiments will attempt bulk heating, preionization, and current profile control. The first experiments will be a test of the principle with a single 200-kW, 28-GHz gyrotron. We then propose to add one additional tube in FY 1979 for high $\beta$ studies, and - assuming successful heating experiments - an additional eight tubes during FY 197980 for an ECH flux conserving tokamak experiment.

Target date for completion of the first experiments on ISX-B with $\sim 200 \mathrm{~kW}$ is December 1978 at an estimated cost of $\$ 0.9 \mathrm{M}$. The second tube can be added in FY 1979 at an estimated cost of between $\$ 0.4$ and $\$ 0.7 \mathrm{M}$, and the experiments with two tubes can proceed starting in the sumer of 1979. Additional power up to $2 \mathrm{MW}$ can be added at an estimated total cost of $\$ 1.75$ to $\$ 5.00 / \mathrm{W}$. These cost ranges reflect current technical uncertainties which will be resolved in the early phase(s) of the program.

This report presents a design description of the proposed experiments, gives results of some theoretical analyses to predict performance, and includes estimates of costs and schedules. 


\section{INTRODUCTION AND SUMMARY}

An experiment with electron cyclotron heating (ECH) is proposed for the ISX-B tokamak. Initially this experiment will answer relevant questions about bulk heating, preionization, and control of the current profile. The latter is of particular interest as a means of optimizing both the gross stability of the plasma and the transport coefficients. The ECH program has been broadened somewhat with the first successful tests of cyclotron masers in the U.S.A. With a dependable source of high power microwaves, it is possible to design an experiment in which electron heating through ECH and ion heating with neutral beams are used concurrently to produce a high $\beta$ plasma in a tokamak. The scaling laws for this new parameter regime can be explored with power sources available within the next two years, and plans can be developed for a test of the concept of a flux conserving tokamak.

ECH is an experimentally proven and reliable means of heating electrons in the interior of a plasma. In the ELMO mirror and bumpy torus (EBT) at ORNL, I electron temperatures of hundreds of kilovolts have been achieved in steady state with quite modest power inputs. Bulk heating of the plasma and a consequent modification of heat transport have been observed with microwave power applied to several tokamaks in the U.S.S.R. ${ }^{2}$ In these experiments the evidence indicates that the heating mechanism is linear and occurs at electron cyclotron resonance. This mechanism is well understood, and theoretical calculations of propagation and heating agree with experiment.

Cyclotron masers, also called gyrotrons or gyroklystrons, are now being developed to produce hundreds of kilowatts of microwave power in steady state. This represents an increment in power of more than an order of magnitude over conventional klystrons; it also represents an improvement of the Russian gyrotrons, ${ }^{3}$ which are presently limited to a millisecond pulse at high power. Cyclotron heating with a sinqle cyclotron maser will equal the ohmic heating $(\mathrm{OH})$ power in ISX, and with several such sources the present $\beta$ limitations of tokamaks can be greatly exceeded, thus producing a high $\beta$ tokamak. The exploration of this high $\beta$ parameter regime is extremely important for the thermonuclear program. A flux conserving 
tokamak ${ }^{4}$ will allow a great reduction in the size of reactors, and, in fact, its successful development may be necessary for the economic feasibility of fusion power.

The ISX tokamak is uniquely suited for a verification of the Russian experiments on ECH and for an increase in power to test the concept of a flux conserving tokamak. The machine is easily accessible, and there are ports and space available for the installation of up to ten cyclotron masers which produce up to $2 \mathrm{MW}$ of microwave power. With the concurrent program on EBT-II, power supplies and equipment can be shared between the two experiments. The personnel of the EBT project have developed great expertise in handling high power microwave sources, and this experience can be used on the tokamak project. There should be no interference between the two experiments, and in particular, there will be no drain of the resources of EBT-II by the ECH program on ISX-B.

A 1 arge amount of neutral beam heating is also planned for ISX-B. Some real advantages are realized by combining the two heating methods. The control of the current profile which is possible with local ECH may be used with advantage to improve the hot ion containment and the stability of the plasma. The direct heating of ions by the neutral beam prevents energy loss from electrons and enhances the plasma pressure. In conjunction the two heating methods give the flexibility needed for an exploration of the high $\beta$ plasma parameter space.

The specific experiment under discussion is the application of 2200 $\mathrm{KW}$ of $28 \mathrm{-GHz}$ microwave power to the ISX device, A tube nf this frequency requires a tokamak magnetic field of $10 \mathrm{kG}$ for cyclotron resonance. Operation at $10 \mathrm{kG}$ would be with relatively $10 \mathrm{w}$ plasma current and hence less than optimum plasma parameters. However, the $\mathrm{OH}$ power input would be less than the available microwave power; therefore, the microwave heating should be able to cause a major increase in temperature and possibly in density. The possibility exists, and is now being examined theoretically, that half harmonic heating at $18-20 \mathrm{kG}$ may be effective. Heating at the second cyclotron harmonic can be tested initially since the machine is expected to operate well at a field of $5 \mathrm{kG}$. The Russian experiment with low fields indicated that second harmonic heating is effective and produces large $B$ poloidal values. 
The cost of the experiment will be governed strongly by the presently unknown cost of the microwave device. A development contract with the Varian Corporation is expected to produce a workable device in CY 1977 for the EBT program. The Varian estimate is that the tube will cost $\$ 100-150 \mathrm{~K}$. The high voltage (HV) modulator and power supply materials costs are expected to be $\$ 50 \mathrm{~K}$; the magnet supply, driver, contingencies, and hardware (waveguide, windows, directional couples) materials costs are expected to be $\$ 200 \mathrm{~K}$. The first gyrotron should be available in 1978 for the ISX experiment. Construction of the HV power supply, modulator, and other components can be completed by the time the gyrotron is available - the main scheduling problem anticipated is the gyrotron itself.

After the initial experiments the addition of more gyrotrons can be considered. Our present estimates are that the addition of one gyrotron will cost a minimum of $\$ 0.4 \mathrm{M}$ and a maximum of $\$ 0.7 \mathrm{M}$. A total of ten gyrotrons would cost between $\$ 3.5 \mathrm{M}$ and $\$ 10.1 \mathrm{M}$, or from $\$ 1.75$ to $\$ 5.05 / \mathrm{W}$. The cost effectiveness is improved by the use of existing neutral beam power supplies for ECH up to the 2-MW levei, which is sufficient for a test of a flux conserving tokamak. One or two additional tubes, with operation at a level of 400-600 kW, should be adequate to produce a high $\beta$ plasma at a toroidal field of $10 \mathrm{kG}$. One tube can be added very easily with no additional HV power supplies.

With these general points in mind, the following list gives the plasma physics and technological questions that can be addressed in the ISX ECH experiment:

(1) an independent test of the observed bulk heating in tokamaks;

(2) a test of the concept of current profile control;

(3) a test of the possibility of preionization by resonant breakdown;

(4) a test of the possibility of control of runaway electrons;

(5) a test of the validity of various heating and absorption models;

(6) a test of various wave launching techniques;

(7) a test of high $\beta$ and flux conserving tokamaks.

A description of the experiment is given in Sect. 3. Costs and schedules are addressed in subsequent sections. The Appendix covers details of the theories relating to profile control, wave damping, accessibility, and 
bulk heating. Preionization and runaway electron control (items 3 and 4 ) have been previously discussed in Ref. 5 . Items 6 and 7 above are not considered in this program plan.

\section{JUSTIFICATION AND RATIONALE FOR THE PROPOSED EXPERIMENT}

\subsection{BASIC NEED: AN ALTERNATIVE TO NEUTRAL INJECTION HEATING}

A recent study of $r f$ heating of tokamaks was conducted by a panel under the direction of L. D. Smullin. ${ }^{6}$ The nanel considered all the available options for rf heating.

All of the $r f$ heating techniques can be regarded as alternatives to neutral injection heating of tokamaks. Neutral beam auxiliary heating is at present more advanced technologically. However, low efficiency at high voltage for positive ion sources and predicted problems with penetration into large devices with modest impurity levels may limit the application of neutral beams in the future. At present, rf heating seems a viable alternative to neutral beam heating and in fact may complement it rather than compete wilh $1 t$.

The conclusions regarding ECH were that the technique has heen utilized effectively in both open and closed geometries and that the main problem with ECH is technical - generating and transmitting the power at nigh frequencies. The panel specifically recommended an early experiment with ECH on a tokamak such as ISX or Doublet IIA. However, the present plan for Doublet IIA does not include electron cyclotron heating.

With the development of the gyrotron, or gyroklystron, the technology of microwave generation has taken a large step forward. The practical unit size at a given frequency has increased by several orders of magnitude. At present the Russian gyrotrons and the prototype American gyrotrons are operating at the 100-kW level with short pulses. Allericall gyrotrons are designed for $\mathrm{cW}$ operation, primarily for EBT specifications, but pulse lengths of tens of milliseconds that are required for ISX-B are effectively steady state.

The important parameter in evaluating auxiliary heating is the ratio of auxiliary heating power to ohmic heating power. For the neutral injection experiments in ISX $-B$, this ratio is projected to be as much as ten, 
compared to a ratio of 1-2 for ORMAK or TFR. The addition of 1-10 gyrotron tubes of ECH to ISX-B will produce an additional power ratio of 1-10. The added power and flexibility are desirable for testing the effects of this power on tokamak equilibria before the construction of an EPR. The neutral beam-to-ohmic heating power ratio of TFTR is expected to be as high as 50, and for EPR it is planned to be in excess of 100 .

\subsection{ADDITIONAL NEEDS: PROFILE CONTROL AND PREIONIZATION}

Aside from $i$ ts usefulness in bulk plasma heating, ECH has additional features which make it attractive.

Profile control has been proposed ${ }^{7,8}$ as one of the supplementary uses of ECH in large tokamaks. By localized heating and careful tailoring of the electron temperature profile, the electron current and $q$ profile can be adjusted. The gross stability and microstability of the plasma depend critically on the q profile. 9,10 Some calculations of heating, incorporating a computer model of plasma transport, are presented in Appendix C. The results show that major changes in the temperature profile are feasible for ISX, with the profiles depending critically on the assumed mechanism of energy transport. Whenever the electron thermal conductivity is dominant the temperature profile can be broadened, but it cannot be peaked off-axis by moving the resonant surface. With energy transport dominated by impurity radiation, off-axis ECH may invert the temperature gradient. The possibility of controlling the q profile in the neighborhood of rational surfaces is contingent on the control of the impurity level. Thus this experiment is ideally suited to a device (such as ISX) with impurity control possibilities.

Preionization by microwave power may be used to form a reproducible current channel at a well defined location away from the wall. Even though the ECH power may not be large compared to the final OH power, for early times when the plasma current is low it will substantially increase the power input. In a large tokamak this will also be useful in reducing the large loop voltage required for breakdown, and in a very large tokamak it can aid in substantially reducing the $\mathrm{OH}$ transformer volt seconds. It may also help reduce the runaway electron current caused by a high initial 
electric field. 5 This may be very important because the runaway electrons can cause impurities to be generated from the limiter or other internal surfaces, and the runaways can damage the limiter and other structures such as divertors.

\subsection{TIMING OF THE EXPERIMENT}

In CY 1977, the first gyrotron for EBT should be delivered from Varian. By CY 1978, the first gyrotron should be available for purchase outside of the EBT contract. This device is expected to be a 28-GHz, 200$\mathrm{kW}$ tube. By this time, enough experience in operating these devices on EBT will have been gained to allow a straightforward application of the technique to a tokamak.

\subsection{ASSESSMENT OF ECH FOR ISX}

In CY 1978, the present ISX vacuum vessel will have been redesigned for a major neutral beam heating experiment, ISX-B. The new vacuum vessel will have ports specifically planned and designed for the introduction of microwave power at the $خ 100-\mathrm{kW}$ level. The machine is designed with a large number of ports and easy access for experimental flexibility; the diagnostics will be more diversified than for any previous experiment with ECH. The machine is large enough for gond plasma containment but not so large that an excessive amount of $r f$ power is needed for the basic heating experiment or for an experiment to explore the high $\beta$ regime. The concurrent experiment with ECH on EBT-II will provide substantial expertise in the techniques of high power microwave energy flow and matching. The minimum power levels contemplated for these experiments are far greater than previously coupled to a plasma at these frequencies. Some cooperation between the two experiments also would be possible in sharing power supplies and other equipment, which would reduce costs significantly. The power supplies for neutral beam injection and for $E C H$ have quite similar parameters, and the particularly advantageous combination of neutral beam heating and ECH is possible on ISX-B. In fact, the neutral beam heating experiments, without $\mathrm{ECH}$, may be done with magnetic fields as $10 \mathrm{w}$ as $12 \mathrm{kG}$ to reduce the high torque on the toroidal field (TF) coils for high $\beta$ 
operation. ISX-B would be operated at $10 \mathrm{kG}$ for the initial ECH experiment, which implies a maximum $\mathrm{OH}$ current of $\sim 70 \mathrm{kA}$ for a reasonable $\mathrm{q}$ at the limiter. This will limit $\bar{n}_{e}$ to $210^{13} \mathrm{~cm}^{-3}$, which is adequate for an $E C H$ experiment. This density, if achieved, will give $\omega_{p}>\Omega$. ISX-B is designed to be operated with elongated plasmas. Under a 1.5:1 elongation the current can be increased by a factor of $260 \%$ for the same q limitations. Such operation may be facilitated by $E C H$ current profile control. ISX presently has ports specifically tailored for ECH. The new liner can have ports located for either ordinary or extraordinary wave launching. Ordinary wave launching can easily be achieved from the outside (low field side), but the maximum central electron density may be sufficient to cause reflection near the center. Extraordinary wave launching can be achieved from the high field side through available access from the top of the tank. However, special techniques may be required for penetration of very dense plasmas. These techniques can be achieved by external or internal structures for both the outside (ordinary wave) and the inside (extraordinary wave), as there is adequate space inside for mounting these structures.

\subsection{NEW DIAGNOSTIC NEEDS AND PROBLEMS}

Theoretical arguments suggest that there may be strong harmonic generation in a dense plasma irradiated by microwaves at the electron cyclotron frequency. ${ }^{11}$ Equipment will be available to measure the radiation at the second, third, and fourth harmonics. There will also be monitors for the fundamental frequency. The second harmonic radiation should be effectively absorbed by the plasma, particularly if ISX is operated at $20-k G$ fields. These measurements will help determine if thresholds exist for the generation process.

There may be some diagnostics problems associated with the use of high power microwaves. The Thoms on scattering equipment may have to be protected. Similarly, the vacuum ultraviolet spectrometer, charge-exchange equipment, and radiometer may all suffer some interference. These diagnostics must have a vacuum path connecting them to the main tank of ISX. Such a vacuum path will usually allow some microwave radiation to irradiate the diagnostic unless screens, beyond cutoff waveguides, or absorbers can be 
introduced in the evacuated region. Equipment which does not have a vacuum path can easily be shielded from the effects of the microwaves.

The previous experience with EBT-S may be of help in solving any shielding problems that arise, since similar diagnostic problems will have a) ready arisen. Experience in operating both ISX-B and EBT-S can be used to benefit the development of solutions for EBT-II where even more severe problems may be encountered.

\subsection{FUTURE POSSIBILITIES}

After the initial experiments on bulk heating, preionization, and profilé control are conducted, it will be possibile to add additional gyrotron units. The physical size of the units is expected to be small in comparison with the neutral beam modules; hence they will not impose

- limits in space. The distinct possibility exists that flux conserving tokamaks can be achieved utilizing a small number of gyrotrons (approximately ten) and that substantial $\beta$ can be achieved with two to three tubes. ISX, being a smallcand flexible experimental device, offers a costefficient means for such experiments.

There are plans for future microwave tube development at $\sim 90 \mathrm{GHz}$ and $\sim 120 \mathrm{GHz}$. High power tubes at these frequencies can be applied effectively to ISX-B as well as to ORMAK Upgrade and TNS.

\section{DESCRIPTION OF THE EXPERIMENTAL EQUIPMENT}

Present theory indicates that the best location for the introduction of microwave power would be on the high field or inside of the vacuum chamber. Extraordinary wave propagation from the high field side does not. oncounter any cutoff region. There are ten ports on the top inside of ISX, six of which are available to this experiment. One port would be needed per microwave tube. Ports were not requested on the bottom inside because of the difficulty of access and equipment location. The port location dictates that the $200-\mathrm{kW}$ gyrotron be located above the midplane of the ISX machine. Additional ports on the outside (low field side) are available for ordinary wave propagation. 
The gyrotron will have a focusing solenoid supplying $\sim 11 \mathrm{kG}$ and magnetic return path. Hence, the device must be kept several feet from the ISX plasma to avoid magnetic interference to the toroidal field and vice versa. The solenoid coils will be supplied by four power supplies, each capable of $30 \mathrm{~V}, 600 \mathrm{~A}$. Also, there will be one supply for the gun magnet capable of $60 \mathrm{~V}$ at $20 \mathrm{~A}$. All five supplies should be located close to the gyrotron on the same platform.

Figure 1 shows the gyrotron, driver, reflex klystron oscillator, and magnetic field power supplies mounted on a high platform on the north side of ISX-B. This location is midway between the proposed neutral injectors and thus minimizes the distance to the capacitor bank power supply, which will be located in the transformer vault north of the PLT beam stand. The total weight of the stand may be as much as $70001 \mathrm{~b}$ and can be supported on existing floor beams.

The gyrotron will be mounted with the electron beam vertical and cathode down. Figure 2 shows the preliminary gyrotron outline and Table 1 shows its tentative specifications. Total water flow for the gyrotron and driver will approach $100 \mathrm{gpm}$ at $250 \mathrm{psi}$. This water flow is approximately $20 \%$ of that required by each neutral beam line. The $21 / 2-i n$.-ID cylindrical output guide will run horizontally above the TF coils to a directional coupler located above the vacuum port. A quasi-optical waveguide rightangle bend will direct the energy down to the vacuum port through a window mounted between the port and the TF coils. By the use of $T E_{o l}$ modes in the guide, the attenuation loss due to the indicated guide length will be less than $1 \%$ of the power. The window on ISX will be purchased from Varian and will be approximately the same as that used on the gyrotron output. It may be necessary to add additional structures (e.g., mirrors or waveguides) inside the vacuum tank. Provision for mounting these structures has been made.

The HV will not be supplied by the EBT gyrotron power supply (as had been considered at one time) but will consist of a capacitor bank and charging supply. There will be no conflict with EBT operation.

The capacitor bank and charging supplies will be capable of supplying the gyrotron electron beam with $\sim 80 \mathrm{kV}$ at $\sim 8 \mathrm{~A}$ for $\sim 100 \mathrm{msec}$. The capacitor bank (composed of a portion of an existing bank) will have a total 
ORNL. DWG 77-8824

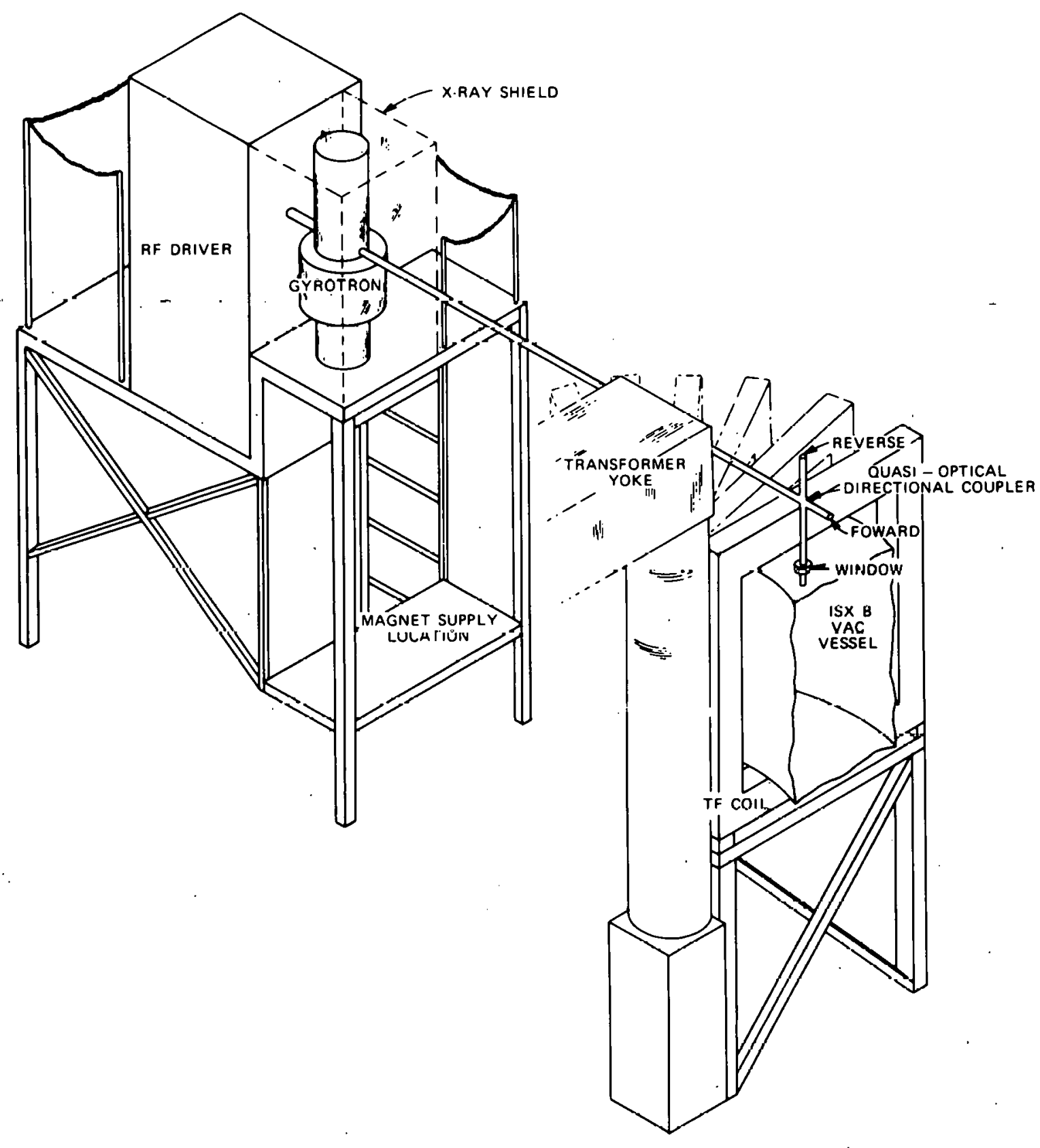

Fig. 1. Schematic view of the gyrotron platform and associated equipment. 


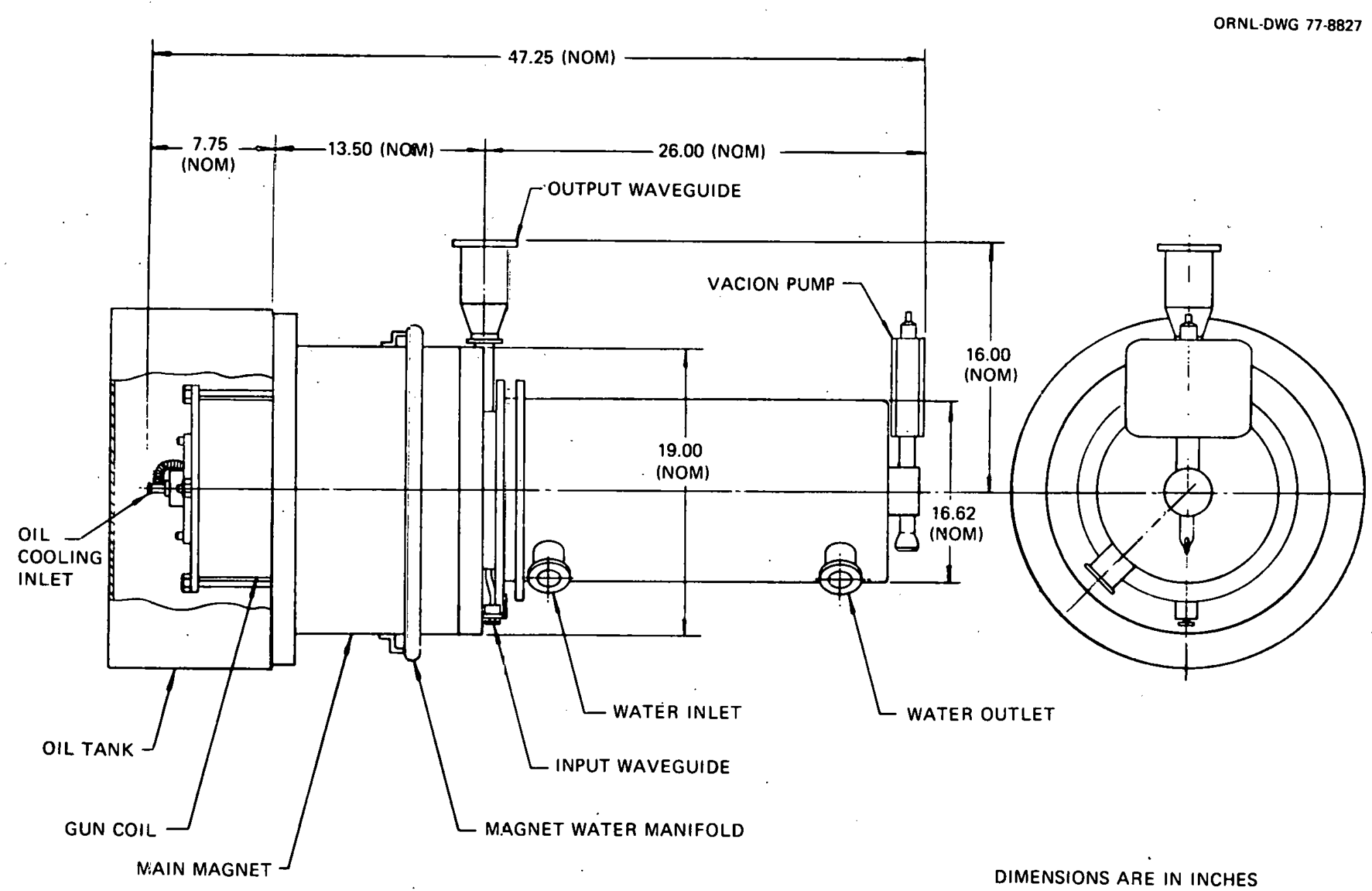

Fig. 2. Preliminary gyrotron outline as conceived by the Varian Corporation. 
Table 1. Tentative specification: type VGA-8000 cyclotron maser ${ }^{a}$

\begin{tabular}{|c|c|c|c|}
\hline Electrical operating parameters & $\underline{\text { Minimum }}$ & $\underline{\text { Maximum }}$ & Typical \\
\hline Beam voltage & $70 \mathrm{kV}$ & $90 \mathrm{kV}$ & $80 \mathrm{kV}$ \\
\hline Beam current & $6 \mathrm{~A}$ & $10 \mathrm{~A}$ & $8 \mathrm{~A}$ \\
\hline $\begin{array}{l}\text { Gun control anode } \\
\text { (with respert. to rathode) }\end{array}$ & $20 \mathrm{kV}$ & $40 \mathrm{kV}$ & $30 \mathrm{kV}$ \\
\hline Heater voltage (ac) & G V & $12 \mathrm{~V}$ & $9 \mathrm{~V}$ \\
\hline Heater current & $4 \mathrm{~A}$ & $8 \mathrm{~A}$ & $6 \mathrm{~A}$ \\
\hline Body current & & $80 \mathrm{~mA}$ & $40 \mathrm{~mA}$ \\
\hline Gun anode current & & $80 \mathrm{~mA}$ & $40 \mathrm{~mA}$ \\
\hline Power output & $150 \mathrm{~kW}$ & $250 \mathrm{~kW}$ & $200 \mathrm{~kW}$ \\
\hline Efficiency & & & $3 n \%$ \\
\hline
\end{tabular}

The VGA-8000 is a cyclotron resonance interaction device which may be
either a single cavity oscillator or an amplifier. The tube prorlures
$200 \mathrm{KW}$ of $\mathrm{CW}$ power output at $28 \mathrm{GHz}$ and in amplifier operation requires
$\mathrm{l} \mathrm{kW}$ of $\mathrm{rf}$ drive power. The tube is liquid-cooled and solenoid-focused. 
capacity of $63 \mu \mathrm{fd}$ at $100 \mathrm{kV}$ and is composed of 160 capacitors rated at 5 $\mathrm{kV}$ and $157 \mu \mathrm{fd}$. A modulator similar to the neutral beam modulators will be used to pulse the HV. The charging supply will be existing G.E. and Del supplies, each capable of $50 \mathrm{kV}$ at $0.5 \mathrm{~A}$, stacked to provide $100 \mathrm{kV}$, and controlled through a G.E. Voltpac and isolation transformers. The charging of the bank will be easily accomplished between ISX shots. A double crowbar system will be used to protect the gyrotron tube against internal arcs. Figure 3 is a schematic, one-line circuit diagram of the ECH system.

In the power supply area, there is considerable room for expansion of the capacitor bank for longer pulses or for the addition of another gyrotron. However, for the addition of many gyrotrons, a more reasonable solution may be to use an existing HV neutral beam supply with a modulator for each gyrotron.

Another possible location for introduction of the microwave energy is from the low field outside of ISX with a horn so oriented as to provide $E$ parallel to $B$. This wave (the ordinary wave) may not be absorbed in one pass, but can, in principle, be entirely absorbed in the plasma after several passes. The existing platform can be lowered and the gyrotron rotated about $i$ ts axis to allow this possibility. The best angle of entry is normal to the field along a major radius. Existing ports on the outside could be used, and the entire structure supporting the gyrotron will need to be lowered to ISX midplane height to allow this.

\section{SAFETY}

Interlocked enclosures will prevent personnel access to areas where lethal voltages are present. In particular, the large $(13 \mathrm{ft}$ by $6 \mathrm{ft}$ by $15 \mathrm{ft}$ ) capacitor bank will be covered on four sides and the top by a grounded, interlocked metal enclosure.

$x$-ray shielding will be provided as necessary to protect operating and maintenance personnel from $x$ rays generated in all high voltage vacuum devices in this system (i.e., the gyrotron, modulator tubes, vacuum switch, crowbar). Personnel will also be protected against injury caused by ionizing radiation. 


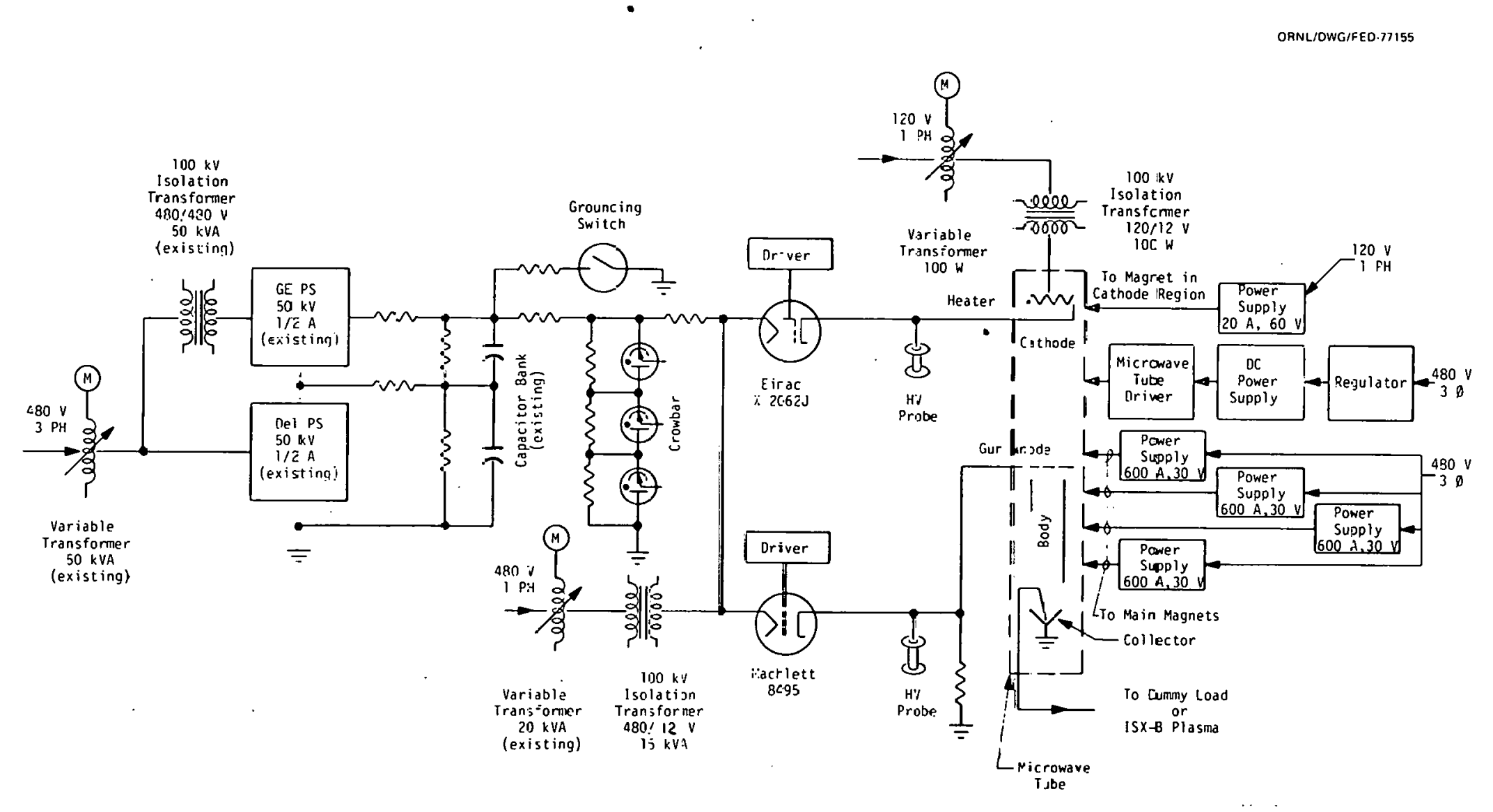

Fig. 3. Schematic one line diagram of ECH system. 
Limited access, shielding, and power absorbers - plus periodic surveys with a monitoring instrument calibrated for use at $28 \mathrm{GHz}$ - will be used to ensure hazard-free rf operation.

\section{ECH PROJECT MILESTONES *}

Mi lestone

1. Gyrotron Tube

1.1 Start Titie II design

1.2 Place purchase order for tube

1.3 Receive tube geometry from seller

1.4 Receive and install tube

1.5 Test complete system and begin operations

2. Driver

2.1 Start Title II design

2.2 Place purchase order for driver

2.3 Receive and install driver

2.4 Test driver

3. Electrical System Components

3.1 Start Title II design

3.2 Complete Title II design of power supply and modulator

3.3 Place purchase order for power supply and modulator components

3.4 Complele and install charging supply $(100 \mathrm{kV}, 1 / 2 \mathrm{~A})$

3.5 Complete and install capacitor bank and crowbar

3.6 Complete and install. modulator

3.7 Test high voltage power supply and modulator
Schedule

August 1977

August 1977

November 1977

October 1978

November 1978

August 1977

October 1977

August 1978

September 1978

August 1977

September 1977

October 1977

February 1978

April 1978

May 1978

August 1978

\footnotetext{
${ }^{\text {TTese milestones }}$ are for the addition of a single $28-\mathrm{GHz}, 200-\mathrm{kW}$ gyrotron to ISX-B.
} 
4. Miscellaneous Systems

4.1 Start Title II design:

Civil and architectural

October 1977

Instrumentation

November 1977

Piping

November 1977

4.2 Start site preparation and construction

December 1977

4.3 Start shop fabrication of parts

December 1977

4.4 Complete Title II design:

Civil and architecturàl

January 1978

Piping

February 1978

Instrumentation

May 1978

4.5 Complcte shop fabrication of parte

September 1878

4.6 Complete construction

October 1978

\section{COST ESTIMATES}

Cost estimates for the addition of a single gyrotron to ISX-B are based on preliminary engineering and the proposed construction schedule; the estimates include the cost of detailed design, procurement, fabrication, and assembly. The estimates were made by the UCC-ND Engineering organization, based on preliminary engineering and bills-of-material produced by UCC-ND engineers and specialists and by using standard estimating procedures. This project will be an addition to ISX-B.

The following table gives a breakdown of the total estimated cost of the experiment on ISX-B with one 200-kW, 28-GHz gyrotron.

\begin{tabular}{lr} 
Summary cost estimate for ISX-B ECH \\
UCC-ND \\
Material \\
$\quad \begin{array}{r}\$ 365,900 \\
143,800\end{array}$ \\
CPFF. \\
$\quad$ Material \\
Labor & 46,000 \\
Engineering & 43,000 \\
Contingency & 149,700 \\
Total project cost & 185,500 \\
\hline
\end{tabular}




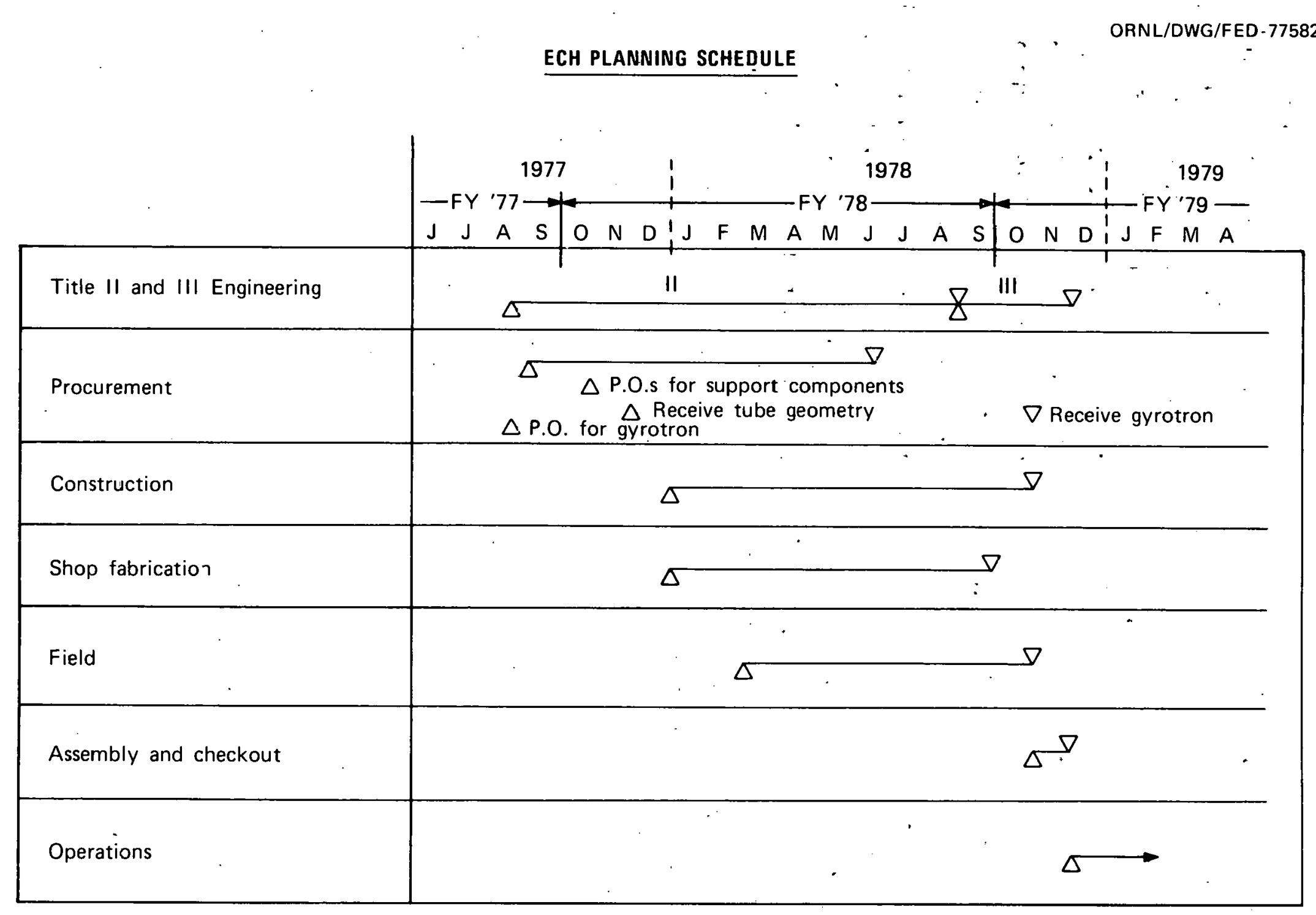




\section{PERMANENT MANPOWER AND MANAGEMENT PLAN}

The ISX-B ECH modification will be designed by the UCC-ND Engineering organization; components will be procured from industry or fabricated in ERDA-OR facilities; assembly will be performed by UCC-ND and a cost-plusfixed-fee contractor. Overall project management and specialized technical input will be provided by ORNL Fusion Energy Program permanent staff.

ISX-B ECH will be operated by the Tokamak Experimental Section of the ORNL Fusion Energy Division, using personnel who presently operate ISX-A. Present plans call for the addition of one staff member skilled in microwave technology; however, training requirements are expected to be minimal. The full operating staff will be needed by October 1978.

The Tokamak Experimental Section of ORNL's Fusion Energy Division will be responsible for the construction and operation of the ISX-B ECH device. A program manager, representing the Tokamak Experimental Section, will manage design and construction of the device in accordance with DMFE MDF procedures. The development and execution of the experimental program will be quided by an experimental planninq committee which is composed of senior physicists from the Tokamak Experimental Section. 


\section{REFERENCES}

1. R. A. Dandl et al., Proc. 5th Conf. Plasma Phys. and Controlled Nuclear Fusion Research, Vol. 2, p. 141 (1975); R. A. Dandl et al., Proc. 6th Conf. Plasma Phys. and Controlled Nuclear Fusion Research, (to be published, 1977).

2. V. V. Alikaev et al., Sov. J. Plasma Phys. 2, 212 (1976); V. E. Golant et al., Sov. Phys.-Tech. Phys. 17, 488 (1972); V. E. Golant et al., Proc. 3rd Intl. Symp. on Toroidal Plasma Confinement, E5, (1973).

3. N. I. Zaytsev et al., Radio Eng. Electron. Phys. 19, 103 (1974).

4. J. F. Clarke and D. J. Sigmar, Phys. Rev. Lett. 38, 70 (1977).

5. A. C. England et a1., High Power Electron Cyclotron Heating in ISX and ORMAK Upgrade at ORNL, ORNL/TM-5425, Oak Ridge National Laboratory, Oak Ridge, Tennessee (May 1976).

6. Report of the Ad Hoc Panel on ro Heating in Tokamaks, ERDA-76/115 (JuTy 1976).

7. J. T. Hogan, "ECH Control of Tokamak Profiles," talk presented at AECDCTR, Germantown, Maryland, October 30, 1973.

8. H. P. Furth (PPPL), private communication, May 1977.

9. Glenn Bateman and Y-K. M. Peng, Phys. Rev. Lett. 38, 829 (1977).

10. R. C. Grimm, J. L. Johnson, and J. Manickam, Phys. Rev. Lett. 38,826 (1977).

11. W. Namkung (ORNL), private communication, May 1977. 
THIS PAGE

WAS INTENTIONALLY

LEFT BLANK 


\section{THEORETICAL APPENDIX}

\section{LINEAR THEORY OF ELECTRON CYCLOTRON HEATING}

There are no theoretical impediments to the successful application of electron cyclotron heating $(E C H)$ to present-day tokamaks. The salient points are:

(1) When launched on the inside, the high magnetic field side of a torus, either the extraordinary $(X)$ or ordinary $(0)$ mode propagates directly to the resonant surface where $\omega=\Omega$, the electron cyclotron frequency.

(2) Large fractions of either the $X$ or the 0 mode are absorbed in a single traverse of the resonant surface. For the ISX plasma, with $\omega_{\mathrm{p}}^{2}=$ $\Omega^{2} / 2, T_{e}=1 \mathrm{keV}$, and wavelength $\lambda=1 \mathrm{~cm}$, we find $90 \%$ absorption of the $X$ mode and $40 \%$ absorption of the 0 mode. Here $\omega_{p}$ is the electron plasma frequency. This calculation assumes a simple waveguide feed into the plasma; the absorption is increased by a more narrow radiation pattern.

(3) The main body of the electrons is heated. The microwave energy goes directly into increasing the perpendicular temperature of the electrons. There is no tendency to accelerate the high energy tail of the electron distribution.

(4) The microwave energy is deposited in a narrow region centered on the resonant surface. The spatial form factor is essentially Gaussian with a half width

$$
\Delta=n_{z} R\left(T / m c^{2}\right)^{1 / 2} \text {, }
$$

where $n_{z}=k_{z} c / w$ is the parallel index of refraction and $R$ is the major radius of the torus. For ISX, with $R=90 \mathrm{~cm}, T_{e}=1 \mathrm{keV}$, and $n_{z}=0.5$ for propagation at $60^{\circ}$ to the magnetic field, one finds $\Delta=$ $2 \mathrm{~cm}$. Since the tokamak minor radius also scales linearly with major radius, only extreme parameters can produce edge heating from rays that propagate directly from the source on the inside of the plasma. This conclusion differs from that of Alikaev et al., 1 who predict edge absorption of the $X$ mode in large machines. Some edge heating is expected along the lines where the resonant surface 
intersects the walls at the top and the bottom of the torus. This edge heating is increased by multiple reflection of waves between the plasma and the wall. An attempt should be made to focus the microwave pattern in the vertical direction with a suitably shaped horn aperture.

(5) The electron energy is quickly spread over a drift surface. Calculations have been made incorporating the ORNL one-dimensional transport code to predict the temporal evolution of temperature profiles.

(6) The electron heating rate is directly proportional to clectron temperature at high density $\left(\omega_{p} \sim \Omega\right)$, while it is independent of temperature at low density. The ohmic heating in tokamaks produces electron temperatures that are large enough for high density ECH.

(7) Even though the $X$ mode may propagate for densities such that $\omega_{p}^{2}>$ $\Omega^{2}$, linear heating is absent above $\omega_{p}=\Omega$ with either the $X$ or the 0 mode.

(8) The heating rates do not depend directly on the plasma shape; heating is equally effective in circular or D-shaped tokamaks.

\section{A. Microwave Propagation in Tokamaks}

At microwave frequencies in tokamaks, the cold plasma approximation is valid except in the region very near to the sycintiron resonance, $\omega=\Omega$, or the upper hybrid resonance, $\omega=\left(\omega_{p}^{2}+s^{2}\right)^{1 / 2}$. In Fig. A.1 the location of these resonances is shown for ISX with a peak density such that $\omega_{p}$ (center) $<\omega$. The $X$ mode may freely propagate from the inside nf the torus, through cyclotron resonance to upper hybrid resnnance. The $X$ mode is cut off on the outside of the torus. The 0 mode may propagate in the entire volume. In Fig. A.2, $\omega_{p}$ (center) $>w$, so that the 0 mode is cut off within the dashed circle, while the $X$ mode is not affected.

A three-dimensional, ray-tracing computer program has been developed and applied to a cylindrical model of a tokamak with toroidal magnetic field but without rotational transform. In Fig. A.3 the ray (energy) trajectories of a bundle of rays of the $X$ mode are followed from the inside of the torus. For the case $\omega_{p}$ (center) $=0.5 \Omega$ in the $x, y$ (cross section) view, the rays pass through cyclotron resonance and approach the upper hybrid resonance layer at normal incidence. In the $x, z$ (principal plane) 


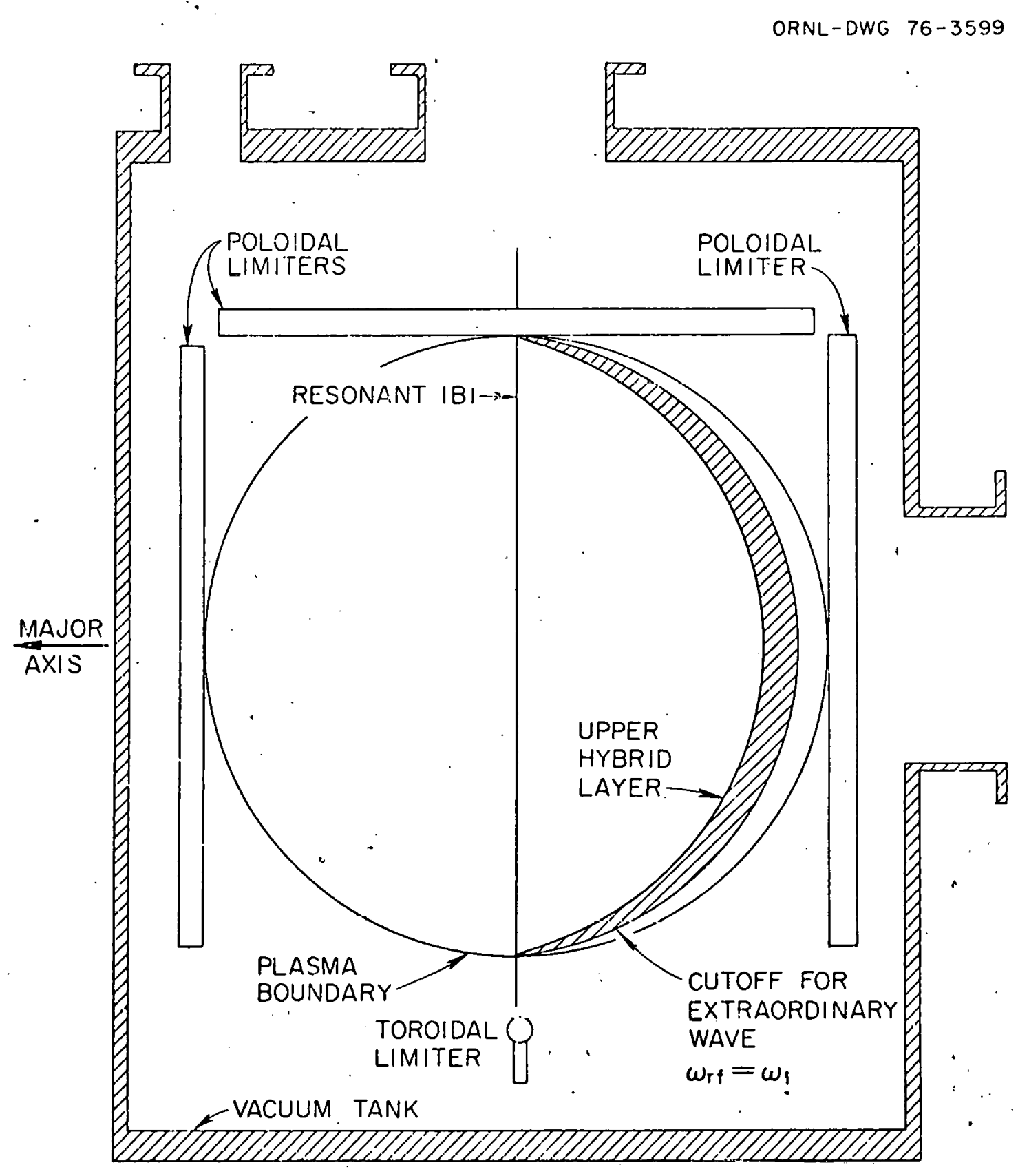

Fig. A.1. Cross section of ISX with a low density plasma and cyclotron resonance in the plasma center. The plasma density maximum is such that $\omega_{p}<\Omega$ at the center of the plasma. 
ORNL-DWG 76-3597

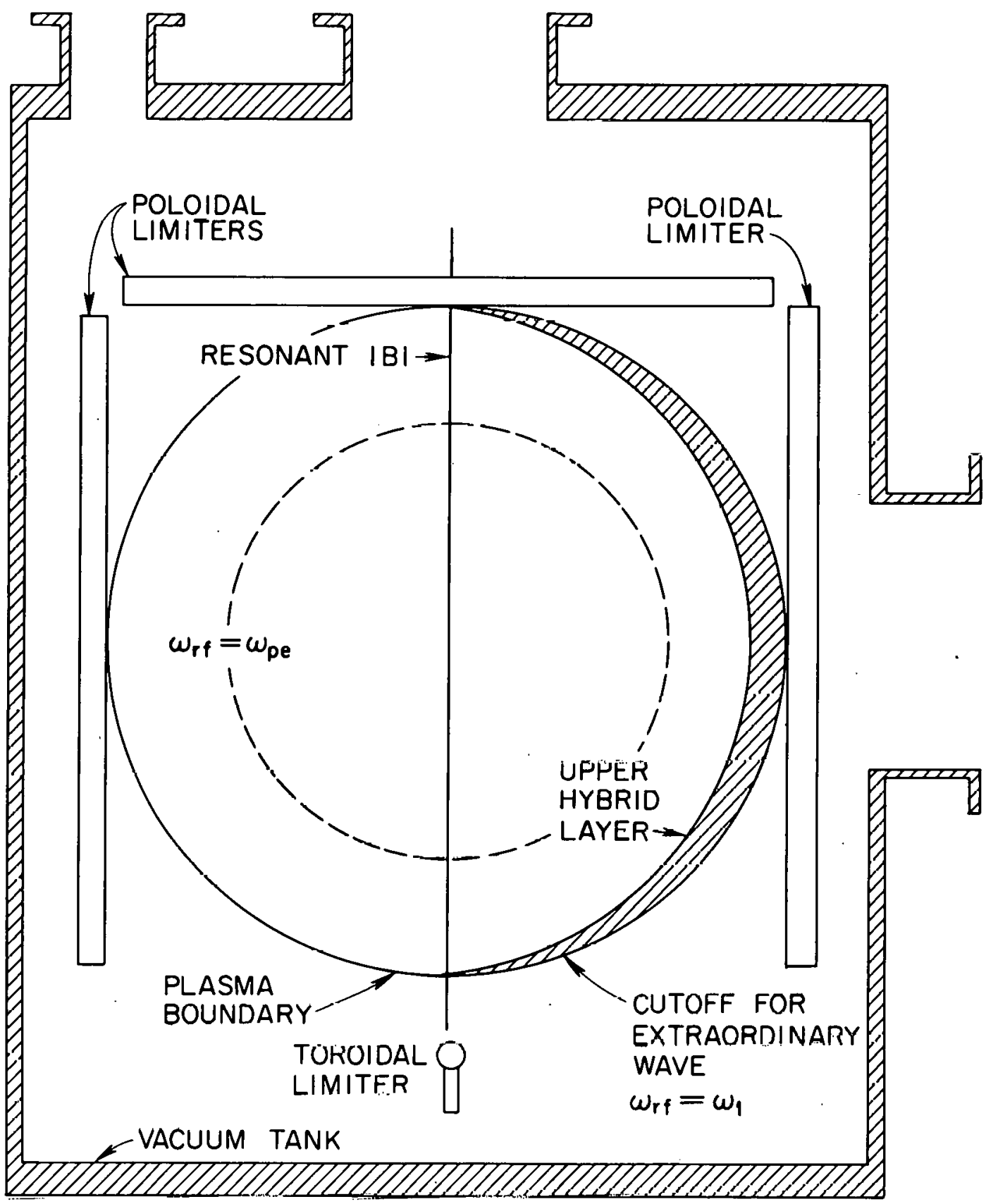

Fig. A.2. Same as Fig. A.1, but with a higher density plasma, such that $\omega_{p}>\Omega$ at the plasma center. 

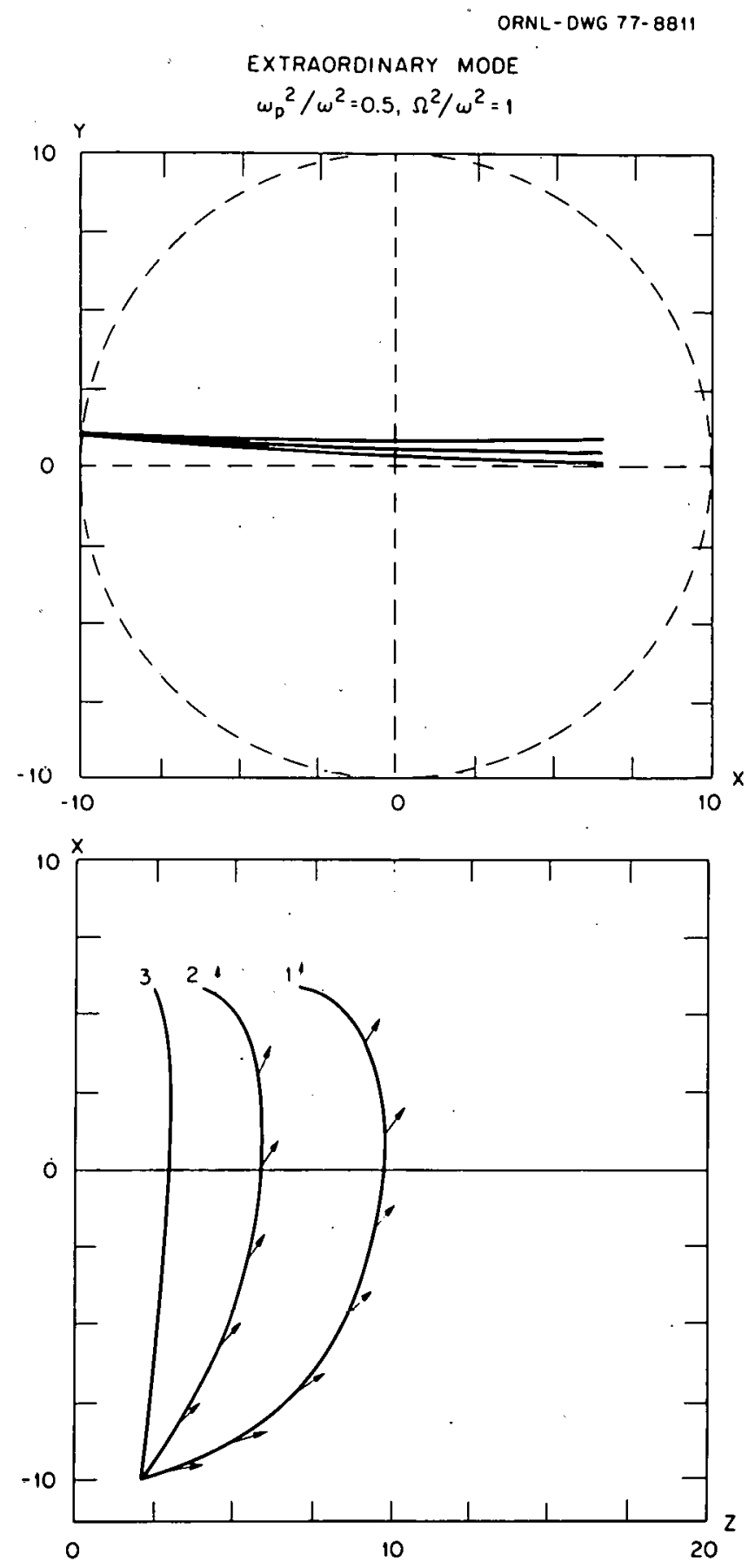

Fig. A.3. The ray trajectories of the extraordinary mode launched from the inside of the torus with $\omega_{p} / \Omega=0.5$. The top plot is $x, y$ view and the bottom plot is $x, z$ view. 
view, the rays turn about and approach the upper layer tangentially. One sees that there is an axial focusing effect in the $x, z$ plane and a flaring effect in the $x, y$ plane, but the rays pass through cyclotron resonance after traversing a short path length in the plasma.

In Fig. A.4, the $X$ mode is followed for a plasma with high central density; $\omega_{p} / \Omega=1.2$ at the center. For small enough angles to the magnetic field the rays are reflected, which will reduce the heating.

\section{B. Electron Heating}

The slow time evolution of the electron distribution function $F(\vec{v}, t)$ with an externally applied rf field has been previously derived by iteration of the Vlasov equation. ${ }^{2}$ For frequencies near the electron cyclotron frequency and wavelengths longer than the electron gyroradius, this quasilinear diffusion equation is

$$
\begin{aligned}
& \frac{\partial F}{\partial t}=\pi\left(\frac{e}{2 m \omega}\right)^{2} \Sigma_{\text {modes }} \\
& \left\{\frac{1}{v_{\perp}} \frac{\partial}{\partial v_{\perp}}\left[\Omega|A|^{2} \delta\left(\omega-\Omega-k_{z} v_{z}\right)\left(\frac{\Omega}{v_{\perp}} \frac{\partial F}{\partial v_{1}}+k_{z} \frac{\partial F}{\partial v_{z}}\right)\right]\right. \\
& \left.\quad+\frac{\partial}{\partial v_{z}}\left[k_{z}|A|^{2} \delta\left(\omega-\Omega-k_{z} v_{z}\right)\left(\frac{\Omega}{v_{\perp}} \frac{\partial F}{\partial v_{1}}+k_{z} \frac{\partial F}{\partial v_{z}}\right)\right]\right\},
\end{aligned}
$$

with $A=\left(E_{x}-i E_{y}\right) v_{1}-\frac{k_{x} v_{1} v_{z}}{\Omega} E_{z}$

in a local coordinate system with the magnetic field in the $z$ direction and the wave vector $\vec{k}$ in the $x, z$ plane. The sum over the microwave field modes is to include an integral over the radiation pattern of the wave launching structurc. The velocity diffusion cüerricienls at a glven spatial point are essentially constant, heating the entire distribution uniformly. The term proportional to $E_{z}$ derived from the microwave magnetic field will preferentially heat electrons with large axial velocities. This term is only important for the 0 mode, propagating almost perpendicular to the magnetic field. 

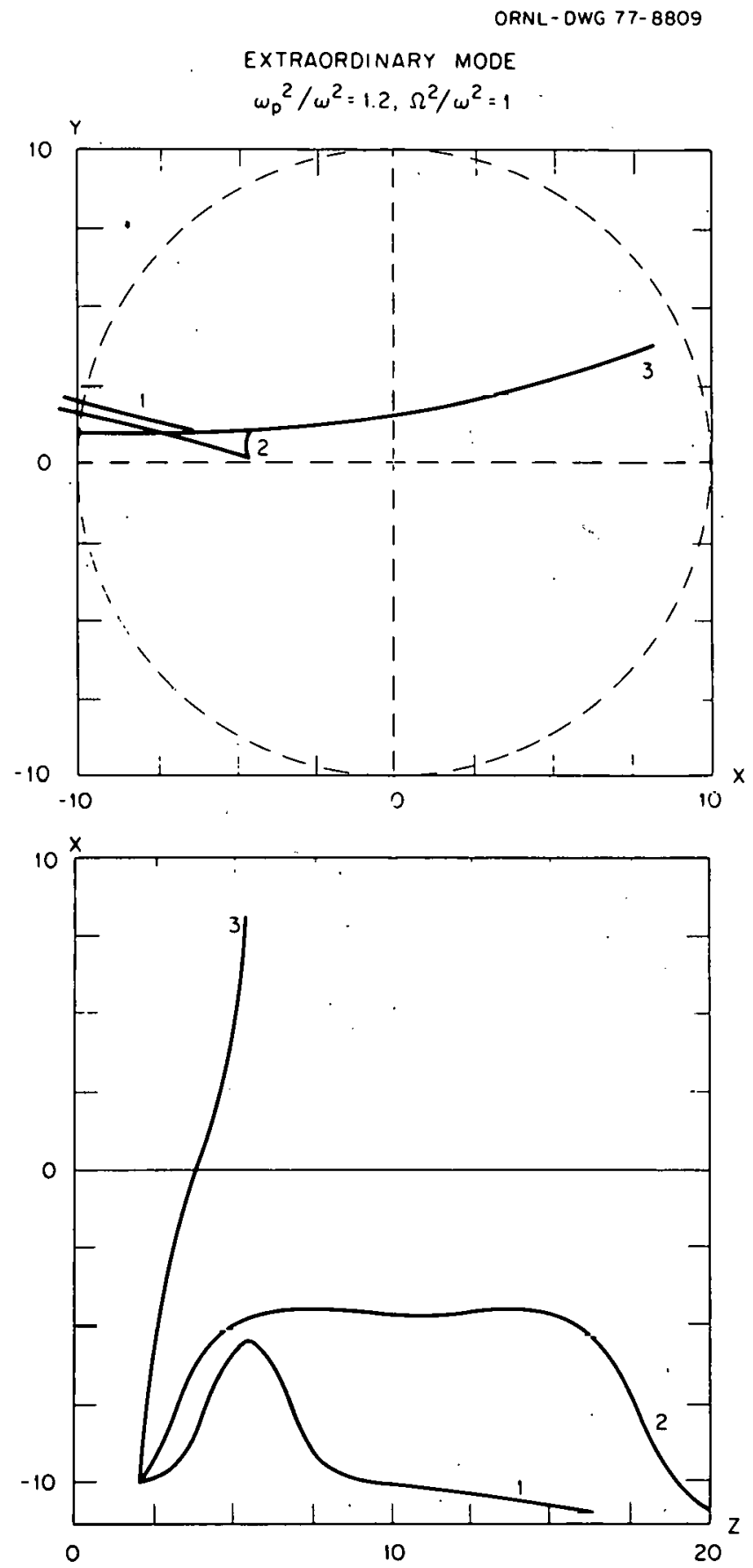

Fig. A.4. Same as Fig. A.3, but with a higher density plasma, such that $\omega_{p} / \Omega=1.2$ at the center. 
The heating rates are small enough so that the electron distribution remains locally Maxwellian, with the local temperature increasing slowly. By expanding the toroidal field near resonance one finds

$$
\Omega(x)=\omega(1-x / R),
$$

and the heating rate per unit volume is

$\frac{d^{2} W}{d t d V}=\Sigma_{\text {modes }} \frac{w_{p}^{2}}{4} \frac{R}{\Delta} e^{-x^{2} / 2 \Delta^{2}}\left|E^{-}-\frac{k}{k_{z}} \frac{x}{R} E_{z}\right|^{2}$,

with

$\Delta=n_{z} R\left(T / m c^{2}\right)^{1 / 2}, \vec{n}=\vec{k} c / \omega$.

The heating is primarily perpendic.ular, although rapidly made isotropic, and is concentrated in a small zone about the resonant surface.

This formula, as it stands, is valid for arbitrary plasma density. 3,4 For high densities, the wave dispersion must be included. In particular, the field component $E^{-}=E_{x}-i E_{y}$ that accelerates electrons is found to vanish at cyclotron resonance for zero temperature, and so the heating rate is proportional to temperature. This in no way affects the conclusion that the entire electron distribution is heated uniformly.

For a single ray propagating into a plasma with $\omega_{p} \simeq \omega$, one finds 5 that the fraction of energy absorbed by the plasma for a single pass through the resonant surface is

$f=1-\exp \left[-\frac{R}{\lambda} \frac{n^{2}}{n_{x}} \frac{T}{m c^{2}} \times\left(\omega_{p}^{2} / \omega^{2}, \vec{n}\right)\right]$,

where $x$ is a complicated function of order unity.

This fraction is plotted in Fig. A.5 for the ISX plasma, $X$ mode, as a function of $n_{z}$, with $n_{x}$ determined by the dispersion. One can see that large $n_{z}$ is required fur large densities, and for $\omega_{p}^{2}>\Omega^{2}$ the absorption is small. In practice the $X$ mode can be launched at an oblique angle to increase absorption. A similar plot for the 0 mode is shown in Fig. A.6. Here the fraction absorbed increases with density. 


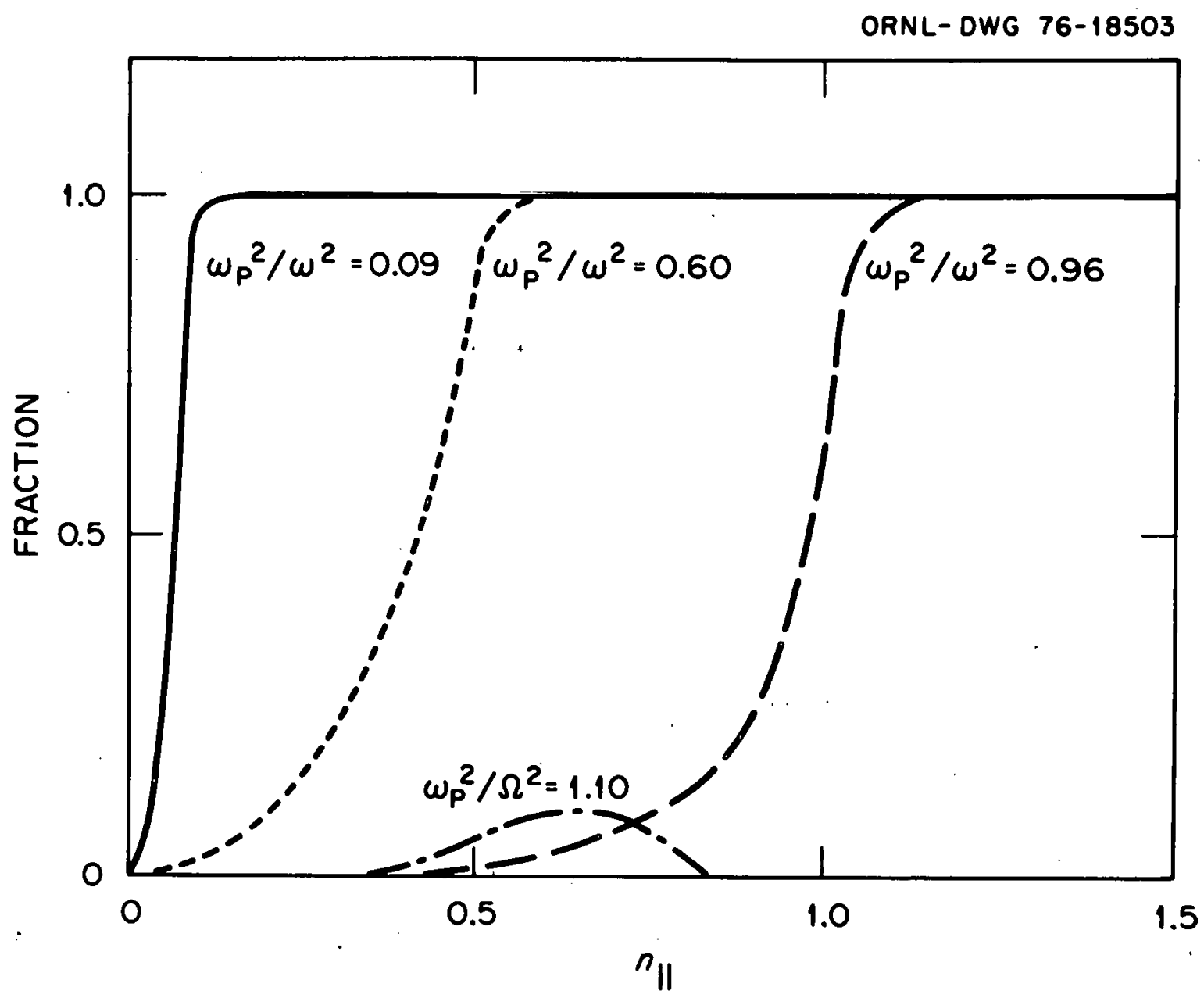

Fig. A.5. Fraction of energy absorbed for the extraordinary mode launched from inside. $\lambda=1 \mathrm{~cm}, B_{T}=10.7 \mathrm{kG}, \mathrm{R}_{0}=80 \mathrm{~cm}, \mathrm{~T}=1 \mathrm{keV}$. 


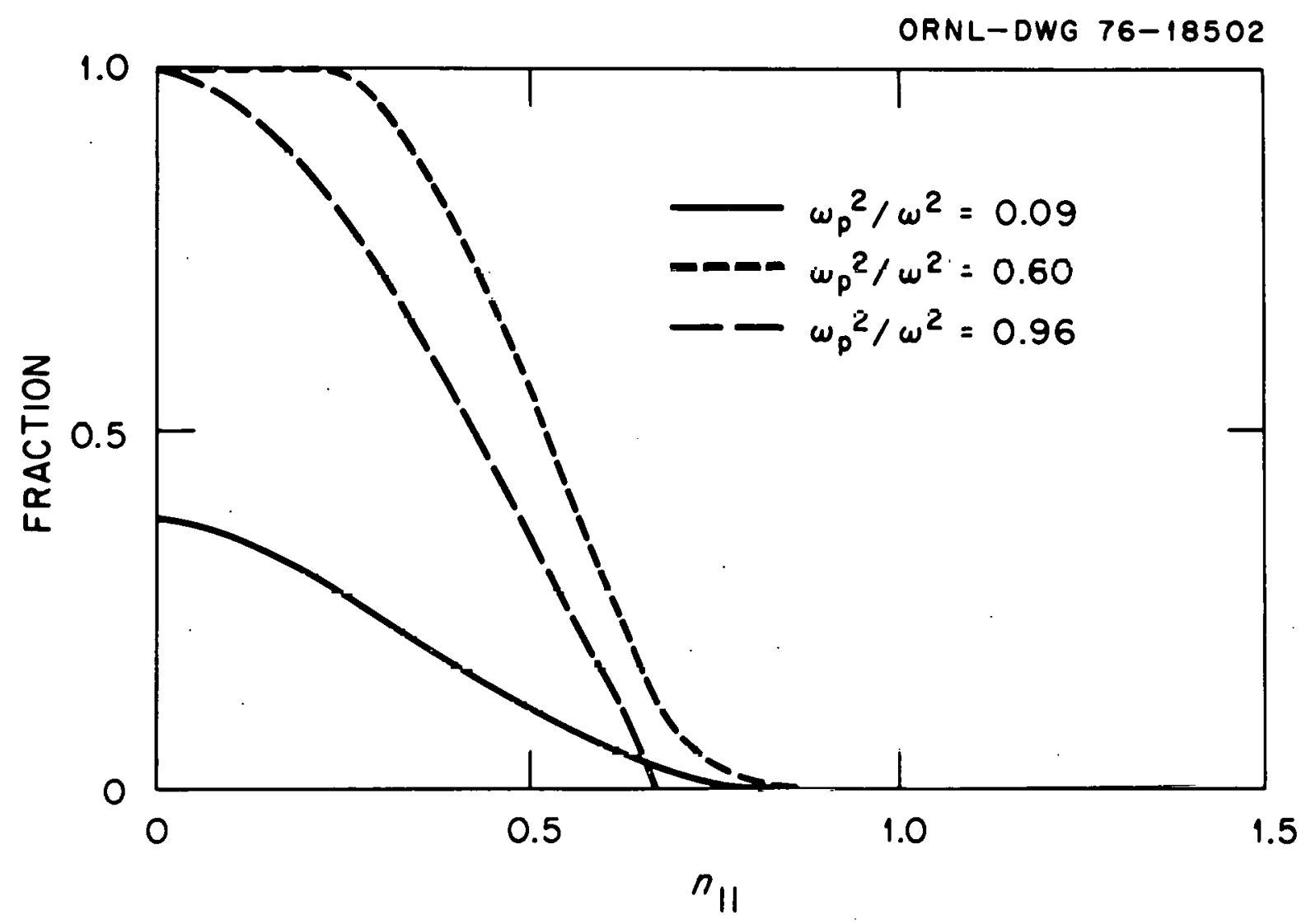

Fig. A.6. Fraction of energy absorbed for the ordinary mode. $\lambda=1 \mathrm{~cm}, B_{T}=10.7 \mathrm{kG}, R_{0}=80 \mathrm{~cm}, T=1 \mathrm{keV}$. 
Results for the spectrum in $n_{z}$ produced by a waveguide aperture oriented perpendicular to the toroidal field are shown in Fig. A.7 for ISX parameters. The absorption fraction has been integrated over the spectrum and is plotted as a function of peak density. One sees that the $X$ mode is more effective. The fraction absorbed may be increased by tilting the waveguide. The fraction of the 0 mode absorbed may be increased by making the spectrum in $n_{z}$ more narrow, but purely perpendicular propagation should be avoided.

\section{Transport Simulation with Electron Heating}

Electron cyclotron heating may be used to heat a plasma locally and therefore is a potentially useful tool for temperature and toroidal current profile control.6 In addition, observation of the plasma response to local heating should enhance our understanding of electron energy transport and the relative importance of transport and radiation. To verify the possibility for local heating, we derive the heating profile in a cylinder using several simplifying assumptions. The coordinates for the calculation are shown in Fig. A.8. The assumptions are:

(1) The microwave field uniformly illuminates the resonant surface.

(2) The power absorption has a Gaussian distribution about the resonance line with a width $\Delta=n_{z} R\left(T / m c^{2}\right)^{1 / 2}$. This is a close approximation to the true line shape derived in Ref. 5.

(3) A radial form factor $I(r)$ approximates the density dependence of Fig. A.7 and the dependence of density on radius.

(4) All the incident power is absorbed after a few reflections. (The walls are expected to reflect and depolarize the radiation that is not absorbed in a single pass.)

The local rate of power deposition is

$$
\frac{d^{2} W}{d V d t}=I(r) \exp \left[-\left(x-x_{0}\right)^{2} / 2 \Delta^{2}\right],
$$

where $x$ is the distance from the magnetic axis in the plane of the torus and normalization of $I(r)$ is determined from the fourth assumption. If the 


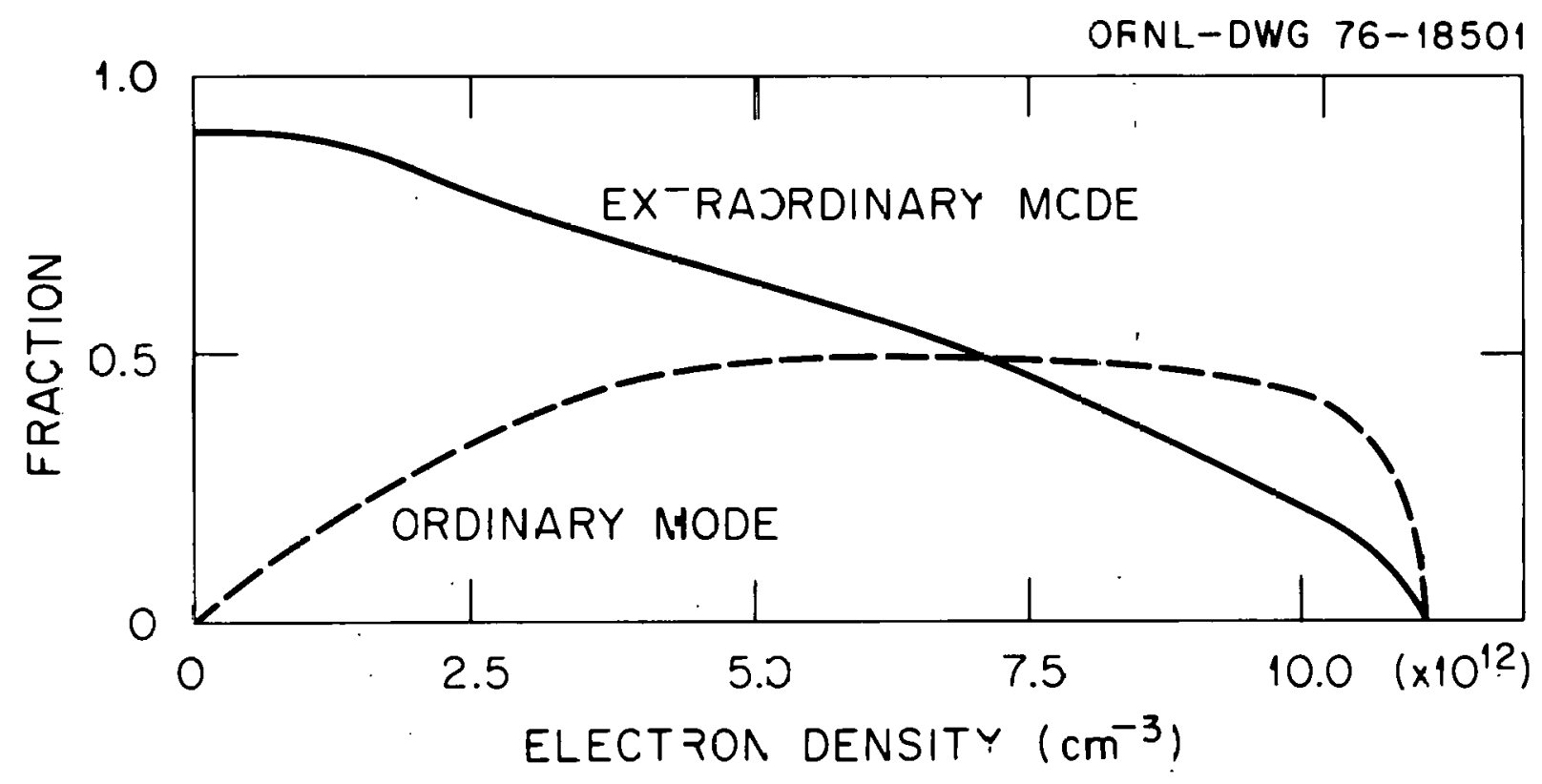

Fig. A.7. Absorption as a function of densizy from waveguide of width, $\lambda / 2 . \lambda=1 \mathrm{~cm}, \mathrm{E}_{\mathrm{T}}=10.7 \mathrm{kG}, \mathrm{R}_{\mathrm{O}}=80 \mathrm{~cm},-=1 \mathrm{keV}$. 
ORNL-DWG 76-14802
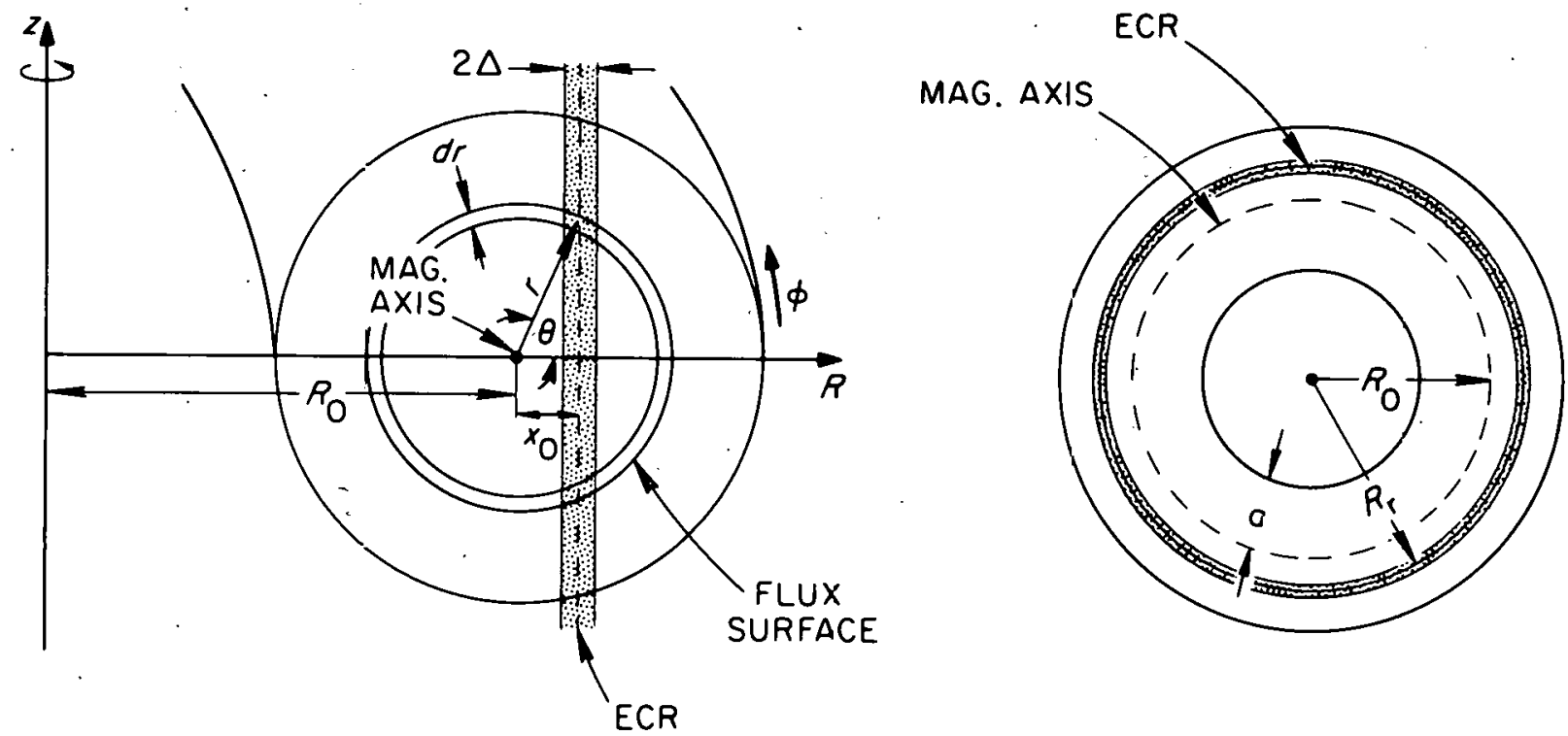

(a) CROSS SECTION VIEW

(b) TOP VIEW

Fig. A.8. Geometry of ECH in tokamaks. 
power absorbed at each point on a flux surface is distributed uniformly near the flux surface and the flux surfaces are concentric circles, then the $E C H$ power density at any radius is

$q_{E C H}(r)=\left\langle\frac{d^{2} W}{d t d V}\right\rangle \theta$,

where $\langle x\rangle_{\theta}$ denotes flux surface average.

As in neutral beam heating calculations, it is useful to normalize the heating profile so that

$q_{E C H}(r)=\frac{P_{E C H}}{V O L} H(r)$,

where $q_{E C H}$ is the total heating power, VOL is the total plasma volume, and $H(r)$ is the shape factor for the heating normalized so that

$\frac{2}{a^{2}} \int_{0}^{a} r H(r) d r=1$.

With $x=r \cos 0$, and $x_{0}=R_{c}-R_{0}$, where $R_{c}$ is the resonance major radius and $R_{0}$ is the torus major radius, the shape factor is

$H(r)=\frac{I(r) \int_{0}^{2 \pi} d \theta \exp \left[-\left(x_{0}-r \cos \theta\right)^{2} / 2 \Delta^{2}\right]}{\frac{2}{a^{2}} \int_{0}^{a} r d r I(r) \int_{0}^{2 \pi} d \theta \exp \left[-\left(x_{0}-r \cos \theta\right)^{2} / 2 \Delta^{2}\right]}$.

For a given absorption profile, $H(r)$ is determined by $x_{0} / \Delta$ and $\Delta / a$. In Fig. A.9, $H(r)$ is plotted as a function of $r$ in four separate plots. For the two plots on the left, the form factor $I(r)$ is taken to be parabol$i c$; for the plots on the right, $I(r)$ is constant. For the two plots at the top, $\Delta=2.2 \mathrm{~cm}$ with several values of $x_{0}$. With this narrow line width, which corresponds to an electron temperature $T=1.2 \mathrm{keV}$ in ISX, local offaxis heating is easily obtained. For constant form factor $I(r)$, some energy is deposited near the edge and easily lost. For the two plots at the bottom, the line width is $\Delta=4.4 \mathrm{~cm}$, corresponding to $T=4.8 \mathrm{keV}$. For this extreme temperature, with constant $I(r)$, appreciable edge heating occurs and the resonant surface should be kept near the center. 

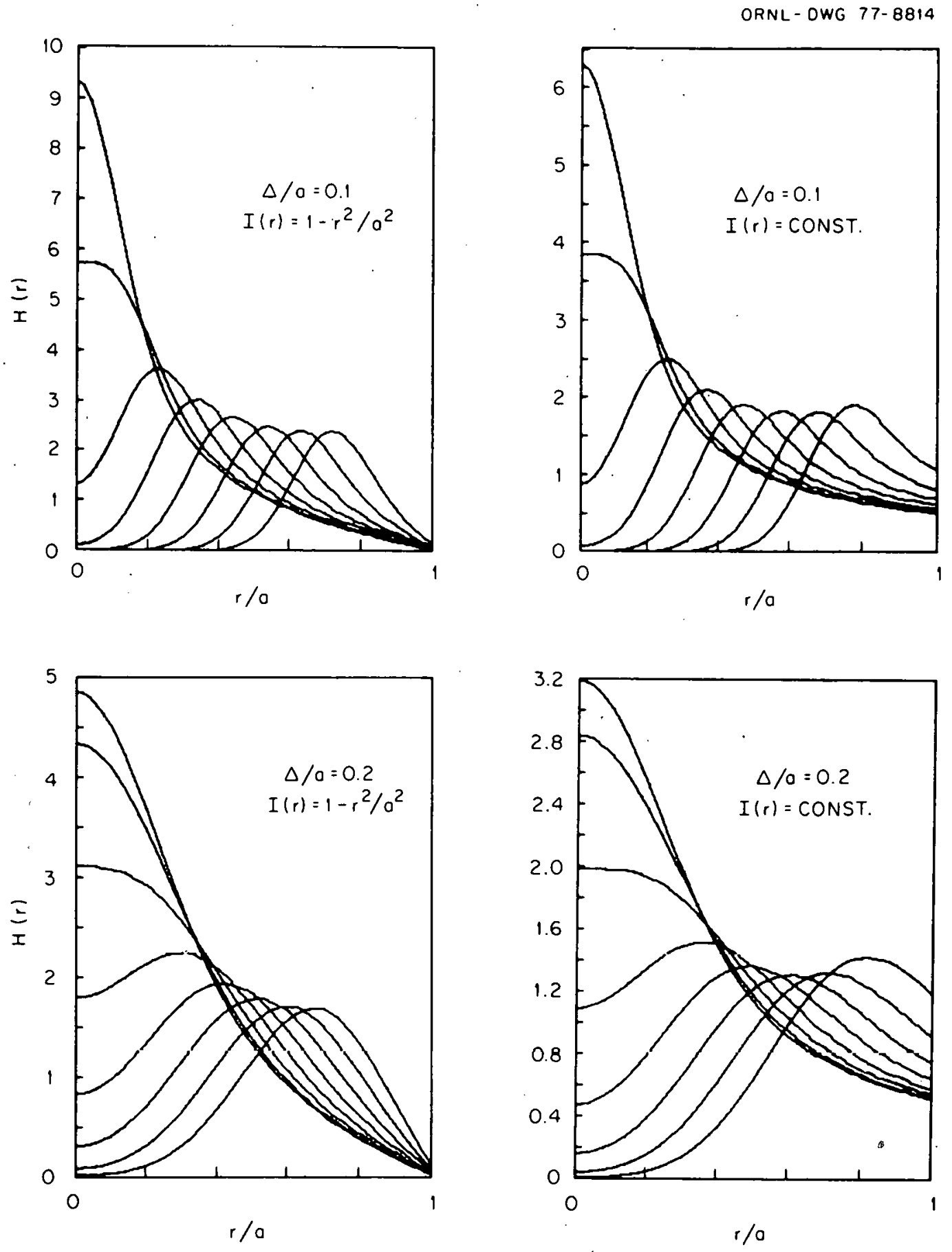

Fig. A.9. The spatial shape factor $H(r)$ with different locations of the resonance zone. The left plots are for a parabol ic form factor $I(r)$, and the right plots are for a constant form factor $I(r)$. The top plots are for the resonance width $\Delta / a=0.1$ and the bottom plots are $\Delta / a=0.2$. Each line represents the resonance location; $x_{0} / a=0$ to 0.7 in increments of 0.1 . 
In Fig. A.10 and Fig. A.11 are shown a series of similar plots. In each plot the resonance position $X_{0}$ is constant and the line width $\Delta$ is varied. For the plots on the left, the form factor $I(r)$ is parabolic; on the right, $I(r)$ is constant.

One concludes that off-axis heating profiles are easily realized in ISX, and only at very high temperature is the line profile broad enough to smear out the resonance. Edge heating only occurs with the assumption of a constant absorption profile $H(r)$, which reflects the density dependence of the $X$ mode in Fig. A.7. It should be emphasized that this edge heating does not occur near the microwave source, but occurs at the intersection of the resonant surface with low density plasma at the wall. Edge heating may be decreased by launching the wave from a microwave horn.

The mechanism for anomalous electron energy loss is one of the least understood features of tokamaks. Several experimental observations which remain unexplained are: (1) $\tau_{E} \propto n_{e}$, (2) the difficulty of producing an electron temperature increase due to neutral beam heating, and (3) hollow electron temperature profiles. Proposed models include trapped particle modes, various transport enhancements due to microturbulence, MHD convective mixing, and radiation due to impurities. While radiation is undoubtedly an important (and in some cases dominant) loss mechanism, the exact nature of impurity transport and radiation is not well enough understood or measured to allow a complete understanding of electron energy losses,

Localized heating away from the plasma axis may be used as a probe of the energy transport mechanism. By observing the evolution of the $T_{e}$ profile, the rate at which heat is transported (and hence the magnitude of the heat conduction) within the plasma may be inferred. Local temperature excursions should be observed around the resonance in the case where heat conduction is low and most of the loss is by radiation; conversely, a general broadening of the profile will result if heat conduction dominates. The relative importance of heat conduction and radiation throughout the plasma may be learned by varying the position of the resonance.

Bolometer experiments on ORMAK indicate that the radiation level rises in response to injection. The increased radiation may be due to an increased impurity level, and there are two possible reasons for this increase. The fast ions which are lost to the wall may desorb impurities 

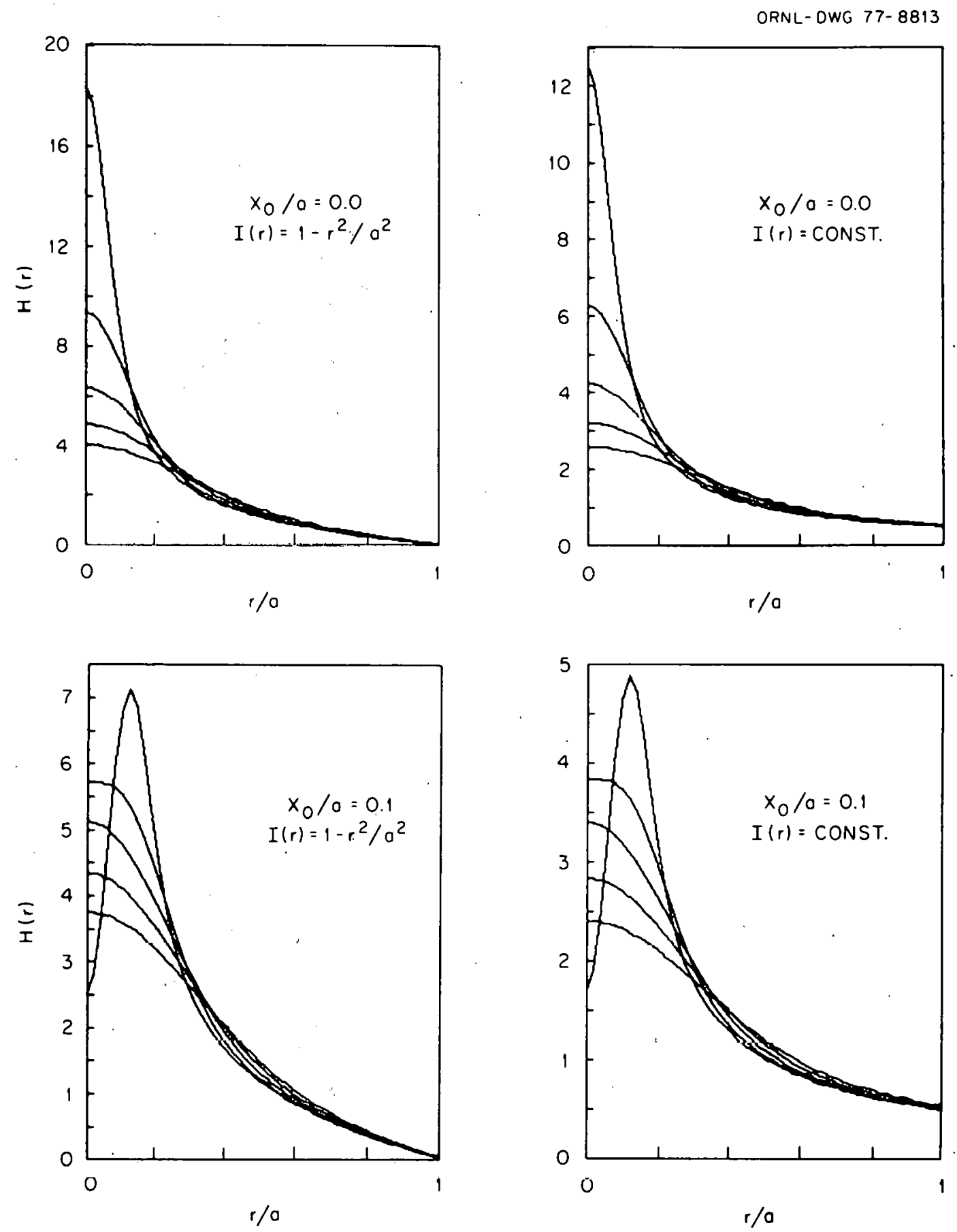

Fig. A.10. The spatial shape factor $H(r)$ with different widths of the resonance zone. The left plots are for a parabolic form factor $I(r)$ and the right plots are for a constant form factor $I(r)$. The top plots are for the resonance location $x_{0} / a=0.0$ and the bottom plots are $x_{0} / a=0.1$. Each 1 ine represents the resonance width $\Delta / a=0.05,0.1$, $0.15,0.2,0.25$. 

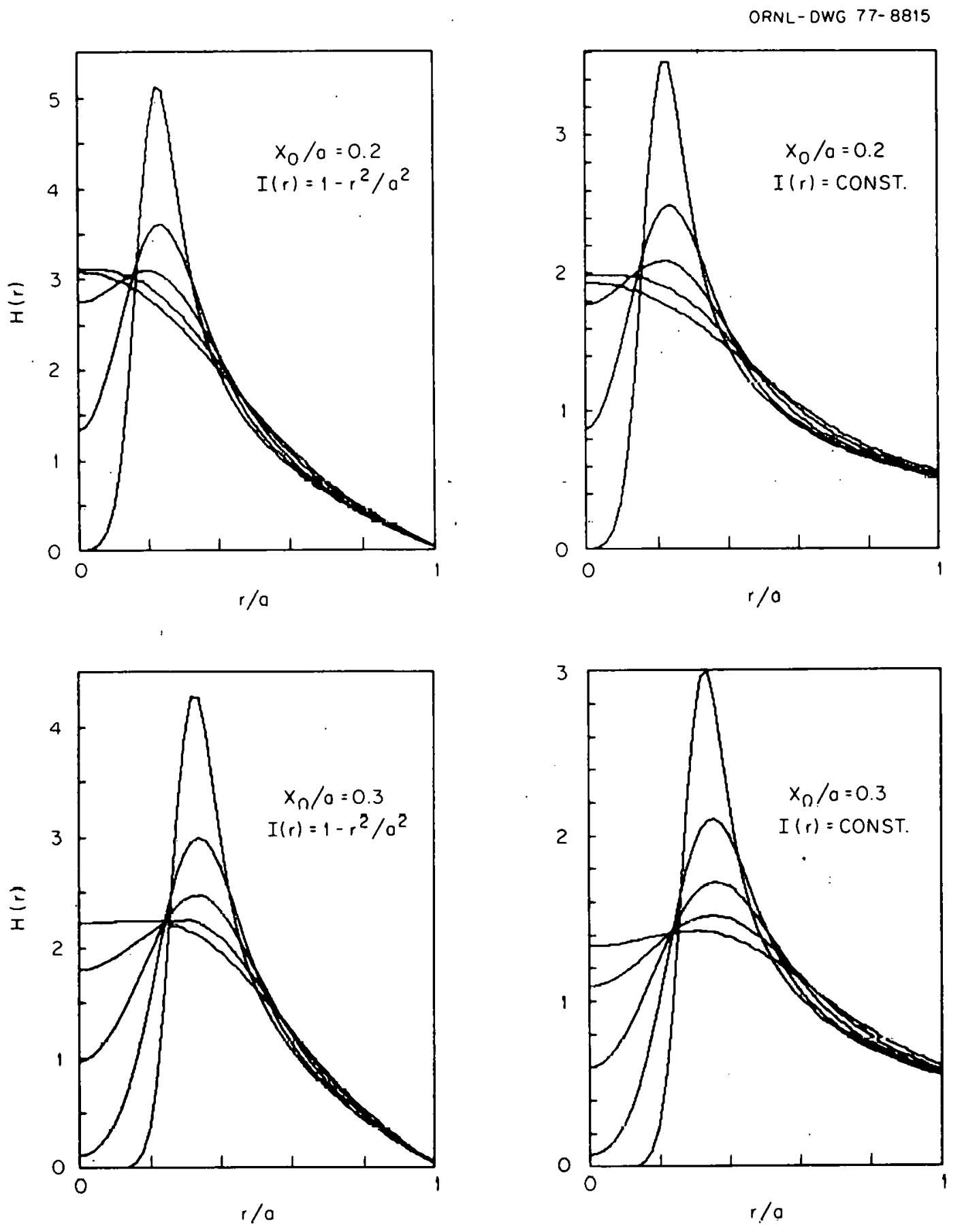

Fig. A.11. Same as Fig. A.10, but with $x_{0} / a=0.2$ for the top plots and $x_{0} / a=0.3$ for the bottom plots. 
from the wall ( $T_{i}$ is too low for sputtering); alternatively, the injected power eventually increases the wall energy load and impurity desorption may be proportional to this load. ECH will differentiate between these alternatives since it increases the wall loading without increasing the fast ion bombardment. Thus, observation of radiation levels in response to ECH will yield information about impurity evolution from the wall.

The amount of profile modification produced by off-axis heating depends on the impurity behavior. This question was studied using the Oak Ridge one-dimensional transport code with $H(r)$ calculated as above, and the major conclusions are:

(1) If the plasma is dominated by heat conduction, the temperature and current profiles are significantly broadened by off-axis heating. With $q_{\text {LIMITER }}=3.5$, it is possible to raise $q(0)$ from 1 to 2 with $200 \mathrm{~kW}$ of heating. This behavior is shown in Fig. A.12, in which the microwave power $P_{E C H}$ is kept constant and the position of the cyclotron resonance is changed. Since the energy transported by heat conduction near the wall is constant, the temperature gradient near the wall is the same for each case and the temperature profiles are monotonically decreasing toward the wall. In Fig. A.13 the radiation power $P_{\text {rad }}$ increases with the heating so that $P_{\text {rad }}=0.7\left(P_{O H}+P_{E C H}\right)$. Some broadening of the temperature profile is seen.

(2) If the plasma is dominated by radiation and the impurity level does not increase with heating power, the temperature profile may be broadened and even inverted by off-axis heating. In this case, heat conduction is too small to prevent local temperature excursions near the EC resonance. In Fig. A.14 the energy transport is dominated by radiation. The temperature peaks are now off-axis .

(3) If the plasma is dominated by radiation and the impurity level is increased proportionally to the heating power, then profile broadening is probably not possible. The increased radiation may even cause the temperature to decrease, as has been observed in some counterinjection neutral beam heating experiments. 


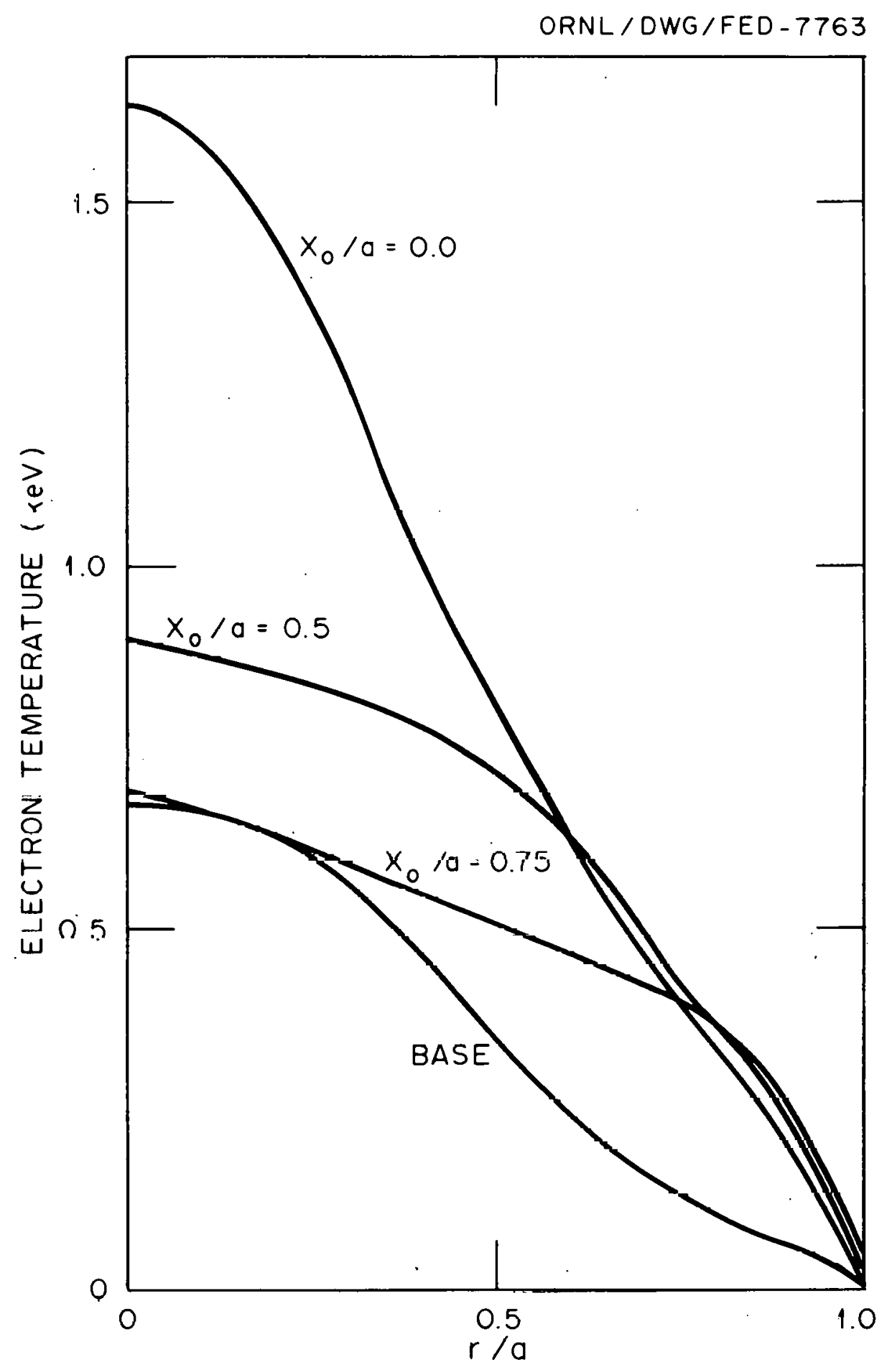

Fig. A.12. Electron temperature resulting from $200 \mathrm{~kW}$ of simulated $\mathrm{ECH}$ heating in ISX-B. Energy loss is dominated by heat conduction with a halo of radiation near the wall. The power radiated in the halo is $P_{\text {rad }}=130 \mathrm{~kW}$ in all cases. 


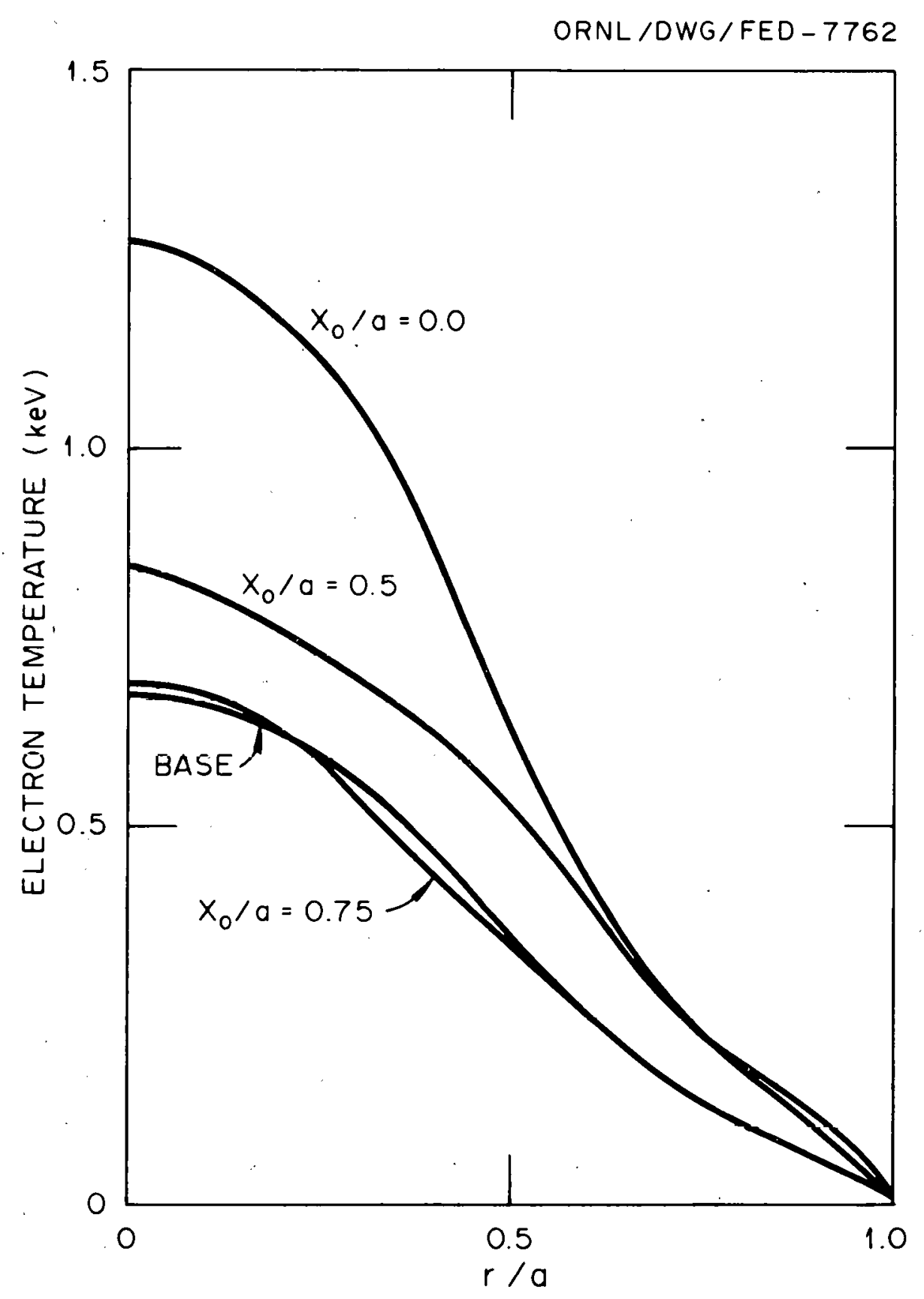

Fig. A.13. Same as Fig. A.12, but the radiation in the halo increases due to heating so that $P_{\text {rad }}=0.7\left(P_{O H}+P_{E C H}\right)$. 


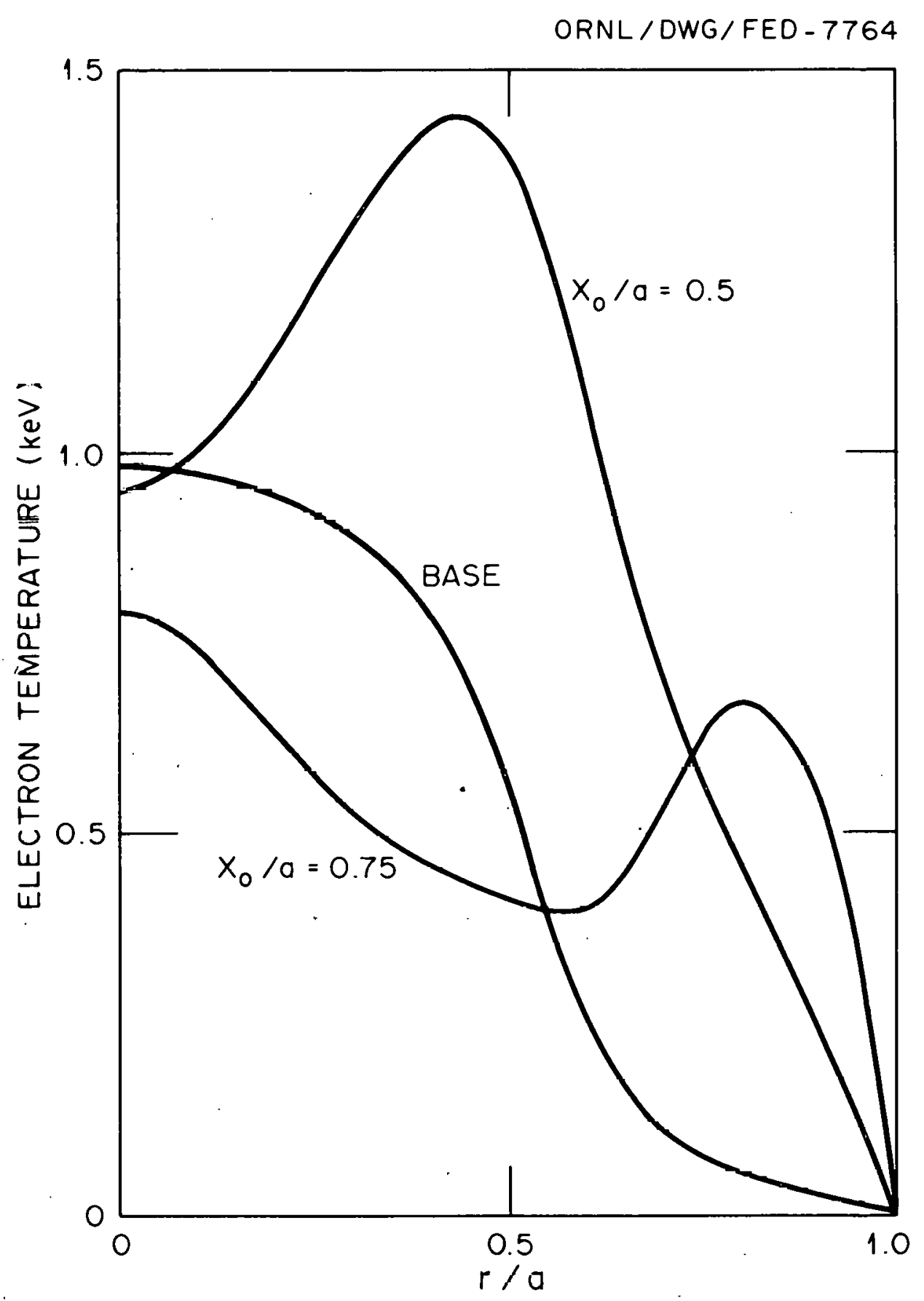

Fig. A.14. Electron temperature for a plasma dominated by radiation. 
(4) The final conclusion is that profile modification will depend on the response of impurities to heating. If impurities can be controlled by gettering or by a divertor, then the temperature and current profile should be easily controlled by selection of the resonance position.

\section{REFERENCES}

1. V. V. Alikaev, Yu N. Dnestrovskii, V. V. Parail, and G. V. Pereverzev, Report No. IAE-2610 (1976), I. V. Kurchatov Institute of Atomic Energy, Moscow, U.S.S.R.

2. C. F. Kennel and F. Engelmann, Phys. Fluids $\underline{9}, 2377$ (1966).

3. 0. E. Eldridge, Phys. Fluids 15, 676 (1972).

4. J. C. Sprott, Phys. Fluids 14 , 1795 (1971).

5. 0. C. Eldridge, A. C. England, and W. Namkung (to be published).

6. W. Namkung and H. C. Howe, Bull. APS, Series II, 21, 1951 (1976). 


\section{THIS PAGE}

\section{WAS INTENTIONALLY \\ LEFT BLANK}


ORNL/TM-6011

INTERNAL DISTRIBUTION

1. D. B. Batchelor

2. L. A. Berry

3. G. L. Campen

4. J. F. Clarke

5. R. A. Dandl

6. H. 0. Eason

7-45. A. C. England

46. P. Gelpi

47. H. C. Howe

48. R. E. Juhala

49. C. M. Loring

50. H. L. Mitche11
51. W. Namkung
52. P. N. Rader
53. D. W. Swain
54. T. White
55-56. Laboratory Records
57. Laboratory Records, ORNL-RC
58. $Y-12$ Document Reference Section
59. ORNL Patent Office
60-61. Central Research Library
62-63. Fusion Energy Division Library
64. Fusion Energy Division Reports office

\section{EXTERNAL DISTRIBUTION}

65. V. V. Alikaev, Kurchatov Institute, Moscow, U.S.S.R.

66. R. A. Blanken, Office of Confinement Systems, Division of Magnetic Fusion Energy, Mail Code G-234, Energy Research and Development Administration, Washington, DC 20545

67. T. Consoli, Centre d'Etudes Nucleaires de Grenoble, Avenue des Martyrs-38-Grenoble, Republic of France

68. N. A. Davies, Office of Confinement Systems, Division of Magnetic Fusion Energy, Mail Code G-234, Energy Research and Development Administration, Washington, DC 20545

69. S. 0. Dean, Office of Confinement Systems, Division of Magnetic Fusion Energy, Mail Code G-234, Energy Research and Development Administration, Washington, DC 20545

70. 0. C. Eldridge, Department of Physics, University of Tennessee, Knoxville, TN 37916

71. H. K. Forsen, Exxon Nuclear Company, 777 106th Avenue, N.E., Bellevue, WA 98004

72. H. P. Furth, Plasma Physics Laboratory, Princeton University, P.0. Box 451, Princeton, NJ 08540

73. V. E. Golant, Ioffe Physical-Technical Institute, Leningrad, K-21, U.S.S.R.

74. R. W. Gould, Profess or of Electrical Engineering and Physics, Building 116-81, California Institute of Technology, Pasadena, CA 81109

75. R. L. Hirsch, Deputy Manager, Science and Technology Department, Exxon Nuclear Corporation, Room 4330, 1251 Avenue of Americas, New York, NY 10020

76-82. T. S. Hsu, Office of Confinement Systems, Division of Magnetic Fusion Energy, Mail Code G-234, Energy Research and Development Administration, Washington, DC 20545

83. H. Ikegami, Nagoya University, Nagoya, Japan

84. H. Jory, Varian Associates, 611 Hansen Way, Palo Alto, CA 94303

85. E. E. Kintner, Director, Division of Magnetic Fusion Energy, Mail Code G-234, Energy Research and Development. Administration, washington, DC 20545 
86. M. M. Larionov, Ioffe Physical-Technical Institute, Leningrad, K-21, U.S.S.R.

87. 0. P. Manley, Office of Applied Plasma Physics, Division of Magnetic Fusion Energy, Energy Research and Development Administration, Washington, DC 20545

88. K. G. Moses, Office of Technical Projects, Division of Magnetic Fusion Energy, Energy Research and Development Administration, Washington, DC 20545

89. V. A. Razumova, Kurchatov Institute, Moscow, U.S.S.R.

90. M. S. Rabinovich, Lebedev Institute of Physics, Academy of Sciences of the U.S.S.R., Leninsky Prospect 53, Moscow, U.S.S.R.

91. D. J. Rose, Department of Nuclear Engineering, Massachusetts Institute of Technology, Cambridge, MA 02139

92. 0. N. Shcherbinin, Ioffe Physical-Technical Institute, Leningrad, K-21, U.S.S.R.

93. H. S. Staten, Office of Development and Technology, Division of Magnetic Fusion Energy, Energy Research and Development Admintstration, Washington, DC 20545

94. K. N. Stepanov, Kharkov Physical-Technical Institute, Kharkov 108, U.S.S.R.

95. V. A. Suprunenko, Kharkov Physical-Technical Institute, Kharkov 108, U.S.S.R.

96. V. T. Tolok, Kharkov Physical-Technical Institute, Kharkov 108, U.S.S.R.

97. J.W. Willis, Office of Confinement Systems, Division of Magnetic Fusion Energy, Energy Research and Development Administration, Washington, DC 20545

08. H. H. Woodson, Chairman, Department of Electrical Enginecring, The University of Texas at Austin, Austin, TX 78712

99. S. Waddle, ERDA-ORO, P.0. Box E, Oak Ridge, TN 37830

100. Research and Technical Support Division, ERDA-ORO, P.0. Box E, Oak Ridge, TN 37830

101-127. Technical Information Center, P.0. Box 62, Oak Ridge, TN 37830 